medRxiv preprint doi: https://doi.org/10.1101/2021.05.28.21258028; this version posted June 3, 2021. The copyright holder for this preprint

(which was not certified by peer review) is the author/funder, who has granted medRxiv a license to display the preprint in perpetuity.

It is made available under a CC-BY-NC-ND 4.0 International license.

\title{
The Immunogenetic Basis of Idiopathic Bone Marrow Failure Syndromes: A Paradox of Similarity and Self-Presentation
}

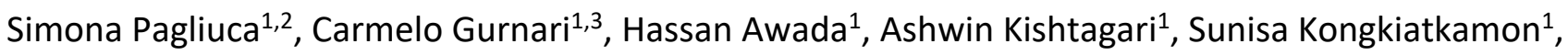
Laila Terkawi $^{1}$, Misam Zawit ${ }^{1}$, Yihong Guan ${ }^{1}$, Thomas LaFramboise ${ }^{4}$, Babal K. Jha ${ }^{1}$, Bhumika J. Patel ${ }^{5}$, Betty K. Hamilton ${ }^{6}$, Navneet S. Majhail ${ }^{6}$, Sofie Lundgren ${ }^{7,8}$, Satu Mustjoki ${ }^{7,8,9}$, Yogen Saunthararajah ${ }^{1}$, Valeria Visconte ${ }^{1}$, Timothy Chan $^{10}$, Chao-Yie Yang ${ }^{11}$, Tobias L. Lenz ${ }^{12,13}$, and Jaroslaw P. Maciejewski ${ }^{1}$.

\footnotetext{
${ }^{1}$ Translational Hematology and Oncology Research Department, Cleveland Clinic, Cleveland, OH, USA

${ }^{2}$ University of Paris, Paris, France

${ }^{3}$ Department of Biomedicine and Prevention, University of Rome Tor Vergata, Rome, Italy

${ }^{4}$ Department of Genetics and Genome Sciences, Case Western Reserve University, Cleveland, OH, USA

${ }^{5}$ Leukemia program, Department of Hematology and Oncology, Cleveland Clinic, Cleveland, $\mathrm{OH}$, USA

${ }^{6}$ Blood and Marrow Transplant Program, Department of Hematology and Oncology, Cleveland Clinic, Cleveland, OH, USA

${ }^{7}$ Hematology Research Unit Helsinki, University of Helsinki and Helsinki University Hospital Comprehensive Cancer Center, Helsinki, Finland

${ }^{8}$ Translational Immunology Research program and Department of Clinical Chemistry and Hematology, University of Helsinki, Helsinki, Finland

${ }^{9}$ ICAN Digital Precision Cancer Medicine Flagship, Helsinki, Finland

${ }^{10}$ Center for Immunotherapy and Precision Immuno-Oncology, Cleveland Clinic, Cleveland, OH, USA

${ }^{11}$ Department of Pharmaceutical Sciences, University of Tennessee Health Science Center, Memphis, TN, USA

${ }^{12}$ Research Group for Evolutionary Immunogenomics, Max Planck Institute for Evolutionary Biology, Plön, Germany

${ }^{13}$ Research Unit for Evolutionary Immunogenomics, Department of Biology, University of Hamburg, Hamburg, Germany
}

\section{Key points:}

- Class II human leukocyte antigen (HLA) loci in idiopathic bone marrow failure (BMF) syndromes are characterized by low functional divergence and decreased peptide binding capabilities, only partially explained by enrichment in risk alleles.

- A superstructure at the interface with the peptide binding site of DRB1 locus, potentially involved in the presentation of self-antigenic specificities, can be identified in BMF patients.

- This immunogenetic pattern may contribute to decrease T-cell receptor repertoire diversity, expand autoreactive T-cell clones and increase autoimmune propensity in BMF.

\section{Word count:}

Abstract: 138

Main text: 5522

References: 91

Tables: 1

Figures: 7

Corresponding Author:

Jaroslaw P. Maciejewski, MD, PhD

Lerner Research Institute NE6

Cleveland Clinic

9620 Carnegie Ave n building, NE6-314, Cleveland, OH

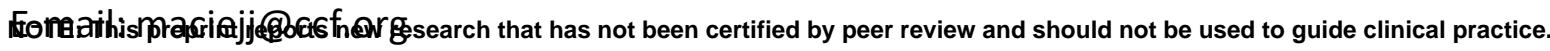


medRxiv preprint doi: https://doi.org/10.1101/2021.05.28.21258028; this version posted June 3, 2021. The copyright holder for this preprint

(which was not certified by peer review) is the author/funder, who has granted medRxiv a license to display the preprint in perpetuity. It is made available under a CC-BY-NC-ND 4.0 International license.

Immunogenetic basis of BMF

Pagliuca et al. 2021

\section{Abstract}

Idiopathic aplastic anemia (IAA) is a rare autoimmune bone marrow failure disorder initiated by a human leukocyte antigen (HLA)-restricted T-cell response to unknown antigens. Immunogenetic patterns associated with self-antigenic presentation remain unclear. Herein we analyzed the molecular landscape of HLA complexes and T-cell receptor (TCR) repertoires of a large cohort of IAA patients and controls. We show that antigen binding sites of class II HLA molecules in IAA are characterized by a high level of structural homology, only partially explained by specific risk allele profiles, implying reduced binding capabilities compared to controls. Few amino acids within the synapsis HLA-DRB1-antigen-TCR, are identified as strongly associated with IAA phenotype. Those structural patterns may affect TCR repertoires, promoting immunological cross-reactivity and autoimmunity. These findings inform on the immunogenetic risk associated with IAA and on general pathophysiological mechanisms potentially involved in autoimmunity.

\section{Introduction}

Among bone marrow failure syndromes (BMF), idiopathic aplastic anemia (IAA) is a hematopoietic stem cell (HSC) disorder mediated by autoimmune T cells. Despite the progress in our understanding of basic disease mechanisms, the strongest evidence for the immune pathogenesis of this disease stems from the successes associated with immune suppressive therapies (IST). ${ }^{1}$ In addition, clinical observations such as evolution of paroxysmal nocturnal hemoglobinuria (PNH) clones escaping from autoimmune selection pressures, as well as somatic loss of human leukocyte antigen (HLA) alleles due to deletion or mutations, further support the immune nature of this disorder. ${ }^{2,3,4,5,6}$

From a pathophysiological point of view, the primum movens of bone marrow destruction is thought to be a class I HLA-restricted process, characterized by cytotoxic T lymphocytes (CTLs) recognition of still unknown HSCs antigens. ${ }^{7,8,9,10}$ Experimental data demonstrating activation of CTLs with oligoclonal expansion and skewing of $\mathrm{CD}^{+} \mathrm{T}$-cell receptor (TCR) repertoire together with an interferon gamma (IFN-y)-driven FAS-mediated apoptosis of HSCs support this hypothesis. $8,11,12,13,14,15$ Furthermore, the imbalance of $\mathrm{CD}^{+}$subsets with dysfunctional $\mathrm{T}$ helper (Th) 1 , Th2 and Th17 responses and consequential impairment of regulatory $T$ cells activities have been demonstrated as additional factors contributing to the aberrant auto-reactivity. ${ }^{16,17,18,19}$ However, because the identity 
medRxiv preprint doi: https://doi.org/10.1101/2021.05.28.21258028; this version posted June 3, 2021. The copyright holder for this preprint

(which was not certified by peer review) is the author/funder, who has granted medRxiv a license to display the preprint in perpetuity.

It is made available under a CC-BY-NC-ND 4.0 International license.

Immunogenetic basis of BMF

Pagliuca et al. 2021

of the eliciting antigens has not been ascertained, the laboratory evidence for $\mathrm{T}$ cell-mediated pathogenesis, albeit compelling, remains only indirect.

In the context of cellular autoimmune reactions, the pivotal role of HLA molecules in mediating the $\mathrm{CD}^{+}$and $\mathrm{CD}^{+}$processes is generally established. Specifically, in IAA a mechanistic involvement of HLA is supported by HLA allele predilection and the modes of immune escape via somatic reshuffles of HLA locus (e.g., loss or uniparental disomy of chromosome $6 p$ or somatic mutations in class I alleles). $2,3,5,20,21,22,23,24$

While external triggers seem essential, genetic disease susceptibility factors (e.g., immunogenetic polymorphisms) appear to be operative. Unlike in other autoimmune disorders, the enrichment of some class I alleles in IAA remains limited to ethnicity-restricted series, ${ }^{2}$ whereas the impact of class II loci on disease susceptibility (e.g., DRB1*15:01) has been historically well documented in multiple

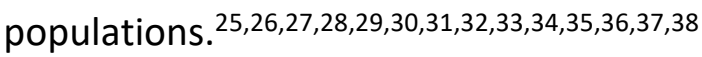

Conceptually, the predilection of certain HLA alleles could be explained by their structural "suitability" to present specific immunodominant peptides. However, the relatively small contribution of individual risk alleles in defining the etiologic fraction of IAA, scarcely adapts the structure/function relationships into a disease-specific autoantigenic profile.

Recent studies have shown that HLA evolutionary divergence (HED), a metric capturing the pairwise Grantham distance ${ }^{39}$ between the peptide binding sites of two homologous HLA molecules encoded by an individual's genotype, correlates with the size of the immunopeptidomic spectrum. ${ }^{40,41,42}$ In this virtue, more structurally divergent alleles may confer a proclivity for more efficient T-cell responses. However, such a postulate, albeit well documented in the context of anti-tumor and anti-infectious immune surveillance, ${ }^{40,41,43,44}$ to date has not been explored in the context of an autoimmune disorder such as IAA. A perhaps simplistic assumption would be that higher allelic divergence may increase the probability of self-antigenic presentation, eliciting autoreactive T-cell responses and explaining the association with autoimmune disease phenotypes.

Herein, we sought to understand the role of HLA functional variability in defining the predisposition and the phenotypic traits of IAA and related disorders. To that end, we performed a large case-control study, in which we analyzed the structural divergence of HLA molecules, its association with risk allele profiles, and the presentation of HSC-related immunopeptidomic specificities. We first performed an allele frequency estimation that helped in the identification and confirmation of the alleles more likely associated with the disease. We then examined the impact of the global genotypic and 
medRxiv preprint doi: https://doi.org/10.1101/2021.05.28.21258028; this version posted June 3, 2021. The copyright holder for this preprint (which was not certified by peer review) is the author/funder, who has granted medRxiv a license to display the preprint in perpetuity. It is made available under a CC-BY-NC-ND 4.0 International license .

Immunogenetic basis of BMF

molecular HLA diversity for both class I and II loci on either disease predisposition or characteristics at diagnosis and clinical outcomes. Finally, we studied how risk and divergent allelic profiles influenced the presentation of HSC immunopeptidome and the TCR repertoire characteristics.

\section{Results}

\section{Association analysis and risk allele imputation}

Out of 430 adult patients with IAA and primary PNH followed at our institution, 263 patients with completed outcomes and precisely asserted diagnosis had DNA for next generation sequencing (NGS)-based HLA typing (Table 1, Fig.S1). For comparison, we built two different control cohorts: i) 960 healthy subjects (HC) from a prevalently Caucasian North-American population, and ii) 510 patients with myeloid neoplasms (MN), with known HLA genotypes (see methods and supplementary appendix). For the analysis of HLA associations, the frequency of each allele was evaluated according to a dominant genetic model, assessing the association strength with class assignment. ${ }^{45}$ Among 8 Ioci, 9 class I and II alleles were identified as differentially distributed between HC and IAA/PNH cohort (Fig. 1A, Table S1), with 4 alleles significantly enriched in IAA/PNH patients, according to a dominant genetic model: DRB1*15:01 DQB1*06:02, $\mathrm{B}^{* 07: 02}$ and DQA1*01:02. Analysis of the additive effect confirmed a strong association with the disease phenotype (Fig.1B, Table S2). The distribution of the significant 4 risk alleles did not differ among IAA and hemolytic PNH groups (Fig.S2A). To determine whether the presence of each IAA risk allele may influence the course of the disease, we performed a logistic regression univariate analysis, which did not reveal any association with malignant progression to myeloid neoplasia (MN) and/or PNH evolution (Fig.S2B-D). However, the presence of DQB1*06:02 showed lower odds in terms of response to IST (OR: 0.48 [ $95 \% \mathrm{Cl} 0.26-0.90], p=0.028$, Fig. S2B-D). By comparison, none of the risk alleles in study were enriched in patients with MN (Table S3). Of note is that those 4 alleles together with $A^{*} 03: 01$ and $C^{*} 07: 02$ belonged to the ancestral haplotype $7.1{ }^{46}$ which was equally distributed across patient and control groups (4\% vs. $5 \%$, respectively, $p=0.753)$. Carriers of at least one risk allele were enriched in the IAA vs. HC with $55 \%$ of the cases harboring $\geq 1$ risk allele (vs. $39 \%$ in $\mathrm{HC}$, OR: 1.94 [95\% Cl 1.47-2.55], p<0.0001, Fig.1B). Furthermore, DRB1*15:01 was associated with DQB1*06:02 in 84\% of cases (patients and HC), as a result of the strong linkage disequilibrium. The frequency of homozygous for class II risk alleles in IAA group was higher than in $\mathrm{HC}$, underscoring the role of the "allelic dose" in disease predisposition (Fig.1C). Risk allele associations, assessed with binomial regression models, were stronger when considering subgroups of patients with increased autoimmune propensity including i) responders to 
medRxiv preprint doi: https://doi.org/10.1101/2021.05.28.21258028; this version posted June 3, 2021. The copyright holder for this preprint

(which was not certified by peer review) is the author/funder, who has granted medRxiv a license to display the preprint in perpetuity. It is made available under a CC-BY-NC-ND 4.0 International license.

Immunogenetic basis of BMF

Pagliuca et al. 2021

immunosuppression, ii) age >20yrs.; iii) IAA with PNH clone; iv) all of the above characteristics (Fig.

1D, Table S4).

When analyzing the allelic frequencies in the pure Caucasian group besides to confirm the strong association with DRB1*15:01 and DQB1*06:02 and the enrichment in $\mathrm{B}^{*} 07: 02$ and DQA1*01:02 in IAA/PNH patients, we observed a slightly increased frequency of few additional more rare alleles (among which the previously reported $\mathrm{B} * 14: 02$, see supplementary appendix). ${ }^{2}$

\section{Low class II HLA divergence as an immunogenetic determinant in IAA patients}

We applied HED concept to explore the immunogenetic configuration of IAA and PNH patients, taking into account the risk allele background and computing HED metrics for all classical I and II loci (A, B, C, DRB1, DQB1, DPB1). Based on the previously validated locus-specific HED metrics, for class II divergence computation, we accounted for $\beta$-chains only, because of the greater variability of $\alpha$ chains in terms of peptide binding sites. ${ }^{41}$ Genotypic differences did not impact the class-related homozygosity configurations of the three cohorts, with subjects with at least one homozygous locus per class being equally distributed in the groups (Fig.2A,B). When we investigated the organization of global class I and II HED (mean of HED scores for each class) in patients and control groups, no differences were observed for class I (IAA vs. HC: $p=0.411$ or IAA vs $M N p=0.189$, Fig.2C). Conversely, a lower mean class II HED was found in IAA/PNH cohort vs. HC ( $p=0.033$; Fig.2D), involving specifically DRB1 (adj. $p=0.028)$ and DQB1 (adj. p=0.028) loci (Fig.2E,F). Associations with lower class II and locusspecific divergence were more evident when we applied generalized linear regression models to predict the risk of immune-enriched disease phenotypes (Fig.3A, Table S5). This pattern was confirmed also when considering only Caucasian subjects (see supplementary appendix and Table S6). No differences compared to controls instead were found when analyzing mean class I and class II HED metrics in MN cohort (Fig. 2A-B, of note is that MN were characterized by a higher HED in locus B compared to $\mathrm{HC})$.

When the additive effect of the presence of risk alleles on class II HED configurations was analyzed, we observed that lower locus specific HED was independently associated with IAA/PNH phenotype (Fig.3B). Interestingly, HC carrying DRB1*15:01 had lower class II and locus-specific HED compared to non-carriers (Fig.S3A, B), whereas in IAA both class II and DRB1 divergences were globally reduced either in presence or in absence of this risk allele (Fig.S3C,D). Nevertheless, patients without 
medRxiv preprint doi: https://doi.org/10.1101/2021.05.28.21258028; this version posted June 3, 2021. The copyright holder for this preprint (which was not certified by peer review) is the author/funder, who has granted medRxiv a license to display the preprint in perpetuity. It is made available under a CC-BY-NC-ND 4.0 International license .

Immunogenetic basis of BMF

DRB1*15:01 had a significantly lower mean class II $(p=0.0005)$ and DRB1 HED $(p<0.0001)$ compared to HC (Fig.3C,D). A similar pattern was seen in DQB1 HED among non-carriers of DQB1*06:02 (Fig. 3E,F). When for comparison purposes we examined another autoimmune disease cohort (type 1 diabetes [T1D]), we also found a lower divergence in class II loci ( $p=0.00058)$ and in DRB1 locus compared to HC ( $p=0.00104$; Table S6; Fig.S4 A, B, C). Binomial regression analysis confirmed lower HED in DRB1 locus as a predictor of T1D (OR: 0.97 [95\% CI 0.95-0.99], p= 0.00235, Fig S4D). Indeed, it is noteworthy the established role of DRB1*15:01 as a protective allele in T1D (Fig. S4D), as well as the different risk allele profile dominated by DRB1*03:01 and DRB1*04:01. ${ }^{47}, 48,49$

To identify alleles structurally similar to those identified as risk alleles in class II, we simulated the range of HED scores between DRB1*15:01/DQB1*06:02 and the pool of alleles present in DRB1 and DQB1 loci in IAA/PNH patients and HC (Fig.4A-C). In DRB1 locus, a lower divergence with DRB1*15:01 was obtained for alleles within DRB1*15, DRB1*16, DRB1*04 and DRB1*01 supertypes (Fig.4A; Table S7). Combined genotypic frequencies of those DRB1*15:01-like alleles were higher in IAA/PNH population (OR: 1.89 [95\% $\mathrm{Cl}: 1.38-2.61], \mathrm{p}=7.22 \mathrm{e}-05$ ) and in cases with immune-related phenotypes compared to HC (Fig.4B). Analogous results were observed for DQB1 locus and DQB1*06 supertype (Fig.4C, D; Table S8).

When we studied whether HLA functional divergence may influence characteristics and outcomes of IAA/PNH patients, we found that class II HED scores correlated directly with the size of PNH clone at diagnosis (Fig.S5A-B; $p=0.00286, r^{2}=0.036$ ) and indirectly with age at disease onset (Fig.S5C-D; $p=0.0013, r^{2}=0.021$ ). Univariable cox regression models (based on binomial categorization of mean class I and II HED according to the $50^{\text {th }}$ percentile in HC, Fig.S5E-K), demonstrated lower probability of survival ( $p=0.011)$, higher risk of progression to MDS/AML $(p=0.043)$ and a lower probability of PNH evolution ( $p=0.0004$, Fig.S5J,L) in patients with lower mean class II HED, while no impact was seen for class I HED (Fig.S5G,I,J ).

\section{Recursive analysis of the antigen binding site in DRB1 and DQB1 loci}

To investigate whether low divergent patterns could rely on a specific amino acid composition of the peptide binding site of class II HLA molecules, we analyzed the amino acid structure in the antigen binding site (encoded by exon 2) of DRB1 and DQB1 loci. In DRB1 peptide binding groove, 30 out of 89 amino acid positions were variable. By applying a recursive approach we found strongly correlated with the IAA/PNH phenotype 7 amino acids (Fig. 5A,B; Table S9), enriched in DRB1*15 group and in 
medRxiv preprint doi: https://doi.org/10.1101/2021.05.28.21258028; this version posted June 3, 2021. The copyright holder for this preprint (which was not certified by peer review) is the author/funder, who has granted medRxiv a license to display the preprint in perpetuity. It is made available under a CC-BY-NC-ND 4.0 International license .

Immunogenetic basis of BMF

Pagliuca et al. 2021

all the alleles structurally similar to this supertype. Of note is that most of those residues were nonpolar, possibly affecting the physicochemical configuration of the antigen-binding site of DRB1*15like complexes. When the same analysis was performed on DQB1 locus (Fig.S6A,B; Table S10), the majority of variable amino acids in exon 2 were enriched in $\mathrm{HC}$, with the exception of 2 residues of phenylalanine (Phe/F), both belonging to the DQB1*06 supertype and significantly overrepresented in IAA (Fig.S6A,B).

Because of this lower contribution of DQB1-binding site variability in conferring disease phenotype, our next analysis was focused on modeling antigen interactions within DRB1 locus. When we analyzed the crystallographic structure of the complex DRB1*15:01/DRA*01:01 (PDB: 1BX2), the identified amino acids clustered within the right part of the antigen binding pocket (Fig.5C). Only two of 7 amino acids were different in DRB1*16:01 (indicating higher structural similarity to DRB1*15:01; Fig.5D), while 5/7 residues differed in DRB1*12:01 (more structurally divergent from DRB1*15:01; Fig.5E). We also aligned the crystal structures of DRB1*15:01/DRA*01:01 with three peptides known to have affinity for DRB1 molecules (EBV DNA polymerase, vimentin and myelin binding protein [MBP], see methods) and found two different patterns of interaction within the binding groove: while the peptide portions binding in the left part of the groove tended to assume the same backbone conformation (underlying conservation of the physicochemical characteristics among the structures at this interface), peptide portions allocated within the right side of HLA groove assumed more variable conformations (Fig.6A). To investigate how this structural configuration could affect the TCR binding, we then constructed a model structure of TCR $\alpha$ and $\beta$ chains, DRA*01:01-DRB1*15:01 and CD4 on the reported ternary crystal structure of HLA-peptide-TCR-CD4 (PDB: 3TOE). ${ }^{50}$ Based on the alignment of these three antigenic models, we found that the variable peptide segments (right portion) interacted mainly with the TCR V $\beta$ chain (Fig.6B,C). These findings provided a proof-ofconcept for the importance of this consensus structure in accommodating the interactions with antigen and T-cell specificities within DRB1 locus.

\section{Quantitative thresholds for self-antigenic presentation}

To explore the binding capacity of self-generated peptides possibly involved in AA pathogenesis, we built an in silico HSC-specific proteomic reference and we analyzed all the different DRB1 and DQB1 molecules present in IAA and HC cohorts. We generated 15-mer peptides from 40,614 transcripts assembled from 7724 previously identified HSC proteins. ${ }^{51}$ For each sequence, the mean number of strong and weak binders (see methods) was determined across all the DRB1 alleles, along with their 
medRxiv preprint doi: https://doi.org/10.1101/2021.05.28.21258028; this version posted June 3, 2021. The copyright holder for this preprint (which was not certified by peer review) is the author/funder, who has granted medRxiv a license to display the preprint in perpetuity. It is made available under a CC-BY-NC-ND 4.0 International license.

Immunogenetic basis of BMF

Pagliuca et al. 2021

proteogenomic spectrum (Table S11). Overall, about 10\% of this proteomic reference was found capable of generating self-peptides suitable for the binding of DRB1 or DQB1 molecules (all peptides with a percentile rank of eluted ligand prediction score $<5 \%$-corresponding to strong and weak binders- were considered for this analysis, Fig.7A,B). HLA molecules belonging to the same locus had similar proteogenomic spectra of derived binders. However, quantitative differences in the number of predicted binders were observed across all the alleles (Table S11 \& S12). In particular DRB1*15:01 along with other alleles was identified as structurally similar to the DRB1*15 supertype and was characterized by lower binding capacities compared to other alleles (Fig.7B, C). Analysis of the distribution of the number of binders in $\mathrm{HC}$ and IAA/PNH groups showed significantly lower binding capacities in DRB1 locus in patients vs. controls (Fig.7D). This pattern was observed also in the subgroup of homozygous individuals (HED score 0; Fig.7E). For DQB1 locus immune-peptidomic analysis we accounted for the genotypic associations with DQA1 locus and thus we considered only individuals with known DQA1 allele. DQB1*0602-DQA1*01:02 was predicted as one of the haplotypes with the lowest binding capacities (Fig. S7A-D) and its propensity to bind HSC self-peptides was decreased compared to other DQB1*06:02/DQA1 combinations (Fig.S7B).

To determine whether the findings described above were reproducible across different ethnic groups and populations with unique HLA distributions, we investigated the genotypic and proteogenomic patterns of the DRB1 locus in of IAA patients ( $N=37$, among which $\mathrm{N}=30$ genotyped at 4-digit level) and healthy controls $(\mathrm{N}=128)$ from a Finnish cohort. Consistently with our results, DRB1*15:01 was significantly associated with BMF phenotype (Fig.S8A,B; OR:5.18; $p=0.0001$ ) and divergence in DRB1 locus was lower for IAA patients compared to controls (this configuration was found both for the whole cohort and for non-carriers of DRB1*15:01, Fig.S8C,D). Importantly, as for the main cohort, also in the Finnish one, DRB1 allele distribution was characterized by lower binding capacities in patients vs. corresponding HC.

\section{Insights in TCR repertoires}

To investigate how risk allele profiles and HED configurations may dictate the patterns of T-cell responses, we performed deep TCR V $\beta$ complementary determining region (CDR3) sequencing for 25 patients with IAA. Patients' V $\beta$ CDR3 spectra were compared to those of $130 \mathrm{HC}$. After a downsampling procedure (see Methods), TCR diversity metrics were calculated. As expected, TCR repertoires were characterized by lower diversity compared to HC (IAA vs. HC: $p=5.4 e-08$; number of unique clonotypes: $p=0.012$; mean size clonal expansion: $p=0.512$; Fig.S9A-C). Specifically, diversity 
medRxiv preprint doi: https://doi.org/10.1101/2021.05.28.21258028; this version posted June 3, 2021. The copyright holder for this preprint

(which was not certified by peer review) is the author/funder, who has granted medRxiv a license to display the preprint in perpetuity. It is made available under a CC-BY-NC-ND 4.0 International license.

Immunogenetic basis of BMF

was lower in both DRB1*15:01 carriers and non-carriers compared to controls (Fig. S9D-E). No correlation was found between V $\beta$ TCR diversity metrics and class I or II mean HED (Fig.S9 F-J). To evaluate how HED could impact on the autoreactive disease-associated spectra, we first built a comprehensive compendium of all CDR3 sequences with known specificity identified in literature (see Methods) and blasted the CDR3 sequences identified in our cohorts against this dictionary. Overall, within the identified clonotypic portion of the repertoire $(<2 \%$ of the total), the mean proportion of identifiable autoreactive clonotypes was $14 \%$ in IAA vs. $6 \%$ in HC (Fig.S9L)., while their mean frequency was respectively $0.016 \%$ and $0.001 \%$ (Fig.S9M; p<2e-16). In IAA patients, but not in HC, the productive frequency of those clones inversely correlated with mean class II HED ( $p=1.332 E-19 ; r^{2}=$ 0.041; Fig.S9N), underscoring the clonal expansion of those specificities in patients with lower class II HLA divergence. Almost all of the autoimmunity-associated clonotypic groups were found hyperexpanded in IAA compared to HC (Fig.S90).

\section{Discussion}

In IAA, the autoimmune destruction of hematopoietic progenitor and stem cells is an HLA class I- and II-restricted T cell-mediated process. Here, with a comprehensive immuno-proteogenomic approach, encompassing deep NGS of HLA region, TCR sequencing and HSC specific immunopeptidome binding analysis, we intensively assessed HLA structures involved in disease susceptibility and potentially associated with autoimmune propensity. To that end, we used not only a comparative population of $\mathrm{HC}$ but also two large disease-control datasets.

The quantitative concept of HED relies on divergent allele advantage, stipulating that structural heterogeneity of HLA alleles allows for a wider spectrum of peptides to be presented and thus a higher probability to mount efficient anti-tumor and anti-infectious responses.52,53,54,40 Accordingly, a similar principle should apply to autoimmune diseases, with a higher HED reflecting an increased propensity to T cell-mediated autoimmunity. However, we did not found support for this hypothesis and instead observed that HLA molecules in IAA patients were characterized by a high structural similarity, especially in class II, in part due to enrichment for risk alleles and/or alleles structurally similar to risk alleles. These associations were particularly strong for DRB1 and DQB1 loci. Consistently with previous studies, DRB1*15:01 together with DQB1*06:02 were identified as alleles enriched in IAA and PNH. ${ }^{26,55,27}$ A special mention deserves the fact that HED metrics were found to be low, independently of the presence of risk alleles in IAA/PNH setting. This pattern is explained by the 
medRxiv preprint doi: https://doi.org/10.1101/2021.05.28.21258028; this version posted June 3, 2021. The copyright holder for this preprint (which was not certified by peer review) is the author/funder, who has granted medRxiv a license to display the preprint in perpetuity. It is made available under a CC-BY-NC-ND 4.0 International license .

Immunogenetic basis of BMF

global low divergence of class II HLA molecules seen in BMF cohort. Indeed, in IAA patients the nonrisk alleles were more structurally similar to each other and to the risk alleles and thus may have analogous (albeit not completely overlapping) peptide recognition spectra. This may contribute to decrease the diversity and increase the clonal expansion of TCR specificities in IAA repertoire. Further, a lower locus specific HED was independently associated with disease phenotype also when performing generalized linear regression models tracking the additive effect of class II HLA risk alleles. Reinforcing the idea that this pattern may be present across different ethnicities and ancestry groups, we showed reproducibility of such findings in an independent cohort of Finnish IAA/PNH patients. Also, we found the same low HLA divergence pattern in an autoimmune disease characterized by different risk allele associations and in which, of note, DRB1*15:01 is a protective allele. ${ }^{47}$

Since our genetic models were built on a mixed population and did not allow to confirm the class I risk alleles previously identified in a prevalently pediatric Caucasian cohort, ${ }^{2}$ we performed also a race/ethnicity stratified subanalysis. Hence, among alleles formerly recognized, we could show only a slightly significant enrichment in B*14:02 in Caucasian patients from the North American cohort, and again confirmed the strong association with the class II alleles identified in the main analysis, as well as the low divergence characterizing class II loci. It is possible that the above dissimilarities with the previously reported class I associations ${ }^{2}$ rely on the different age composition of our study cohort, prevalently composed by adult patients (see Supplementary considerations).

In order to deeper analyze the superstructures involved in the decreased divergence within the antigen binding sites, we studied the amino acid specificities found in the variable portion of the antigenic groove of DRB1 and DQB1 molecules with a recursive approach. This analysis enabled the identification of few residues significantly associated with IAA/PNH phenotype, mainly located in pockets involved in antigen and TCR $\beta$ interactions. This analysis, by modeling analogous antigens known to be binders of DRB*15:01 and alleles with structural similarity, allowed us to identify antigen components involved in the preferential self-presentation of BMF patient, potentially associated with impaired T-cell activation.

Consistent with the lower divergence seen in IAA/PNH population, when we analyzed DRB1 and DQB1 binding predictions covering the HSC specific immunopeptidome, we found that for both loci, HLA genotypes had lower binding capacities in patients compared to healthy individuals, both in homozygous and heterozygous settings. If per divergent allele advantage immunocompetence is supposed to be enhanced in case of higher HLA divergence, it is plausible that less divergent loci and, per extension, HLA molecules with lower binding capacities (such as DRB1*15:01 and DQB1*06:02- 
medRxiv preprint doi: https://doi.org/10.1101/2021.05.28.21258028; this version posted June 3, 2021. The copyright holder for this preprint

(which was not certified by peer review) is the author/funder, who has granted medRxiv a license to display the preprint in perpetuity.

It is made available under a CC-BY-NC-ND 4.0 International license .

Immunogenetic basis of BMF

Pagliuca et al. 2021

DQA1*01:02) may increase the risk of immunological cross-reactivity and molecular mimicry with possible pathogen-associated antigens, by that triggering autoimmune diseases. As an example of autoimmune disorder with known self-antigenic specificities, in multiple sclerosis the link among DRB1*15:01, EBV and central nervous system antigens' molecular mimicry is well established, with indirect evidence that impaired CD4+ presentation may elicit aberrant CD8+ responses and autoantibody production. ${ }^{56,57,58,59}$

If risk allele profiles did not impact on clinical outcomes, low divergence in class II was associated with an increased probability of malignant progression in IAA/PNH patients. This finding is in line with the idea that anti-tumor surveillance (previously shown as more efficient in highly divergent class I allele pairs $)^{40}$ could encompass also HLA class II-restricted T-cell responses. ${ }^{60,61,62}$ In this setting, less divergent class II $\beta$ chains may reduce the neoantigen presentation capabilities configuring an immune escape scenario.

Our data demonstrate that in BMFs and potentially in other autoimmune disorders, HLA allele configurations with more specific structural patterns and globally lower functional divergence may contribute to decrease the binding capabilities especially in class II alleles, potentially enhancing antigenic cross-reactivity and, hence, autoimmune propensity.

Taken together our results represent an important advancement in the field of immunogenetics of BMFs with crucial implications also in other autoimmune disorders. Analysis of HLA divergence and identification of DRB1 superstructure may be easily translated in clinical practice for better diagnostic and prognostic orientations paving the way for new therapeutical approaches potentially able to modulate the self-antigenic binding capabilities of class II HLA molecules.

\section{Methods}

\section{Study design and cohort assemblies}

This is a retrospective study evaluating the immunogenomic configuration of antigen-presenting HLA complexes and the TCR repertoires of patients with IAA and PNH (Fig.S1). Two hundred sixty-three patients diagnosed with $\mathrm{BMF}$, along with $20 \mathrm{HC}$ were enrolled, and their peripheral blood and marrow specimens were previously stored, based on their consent to participate to institutional translational research protocols. This study was conducted under the institutional review board of Cleveland Clinic 
medRxiv preprint doi: https://doi.org/10.1101/2021.05.28.21258028; this version posted June 3, 2021. The copyright holder for this preprint

(which was not certified by peer review) is the author/funder, who has granted medRxiv a license to display the preprint in perpetuity. It is made available under a CC-BY-NC-ND 4.0 International license .

Immunogenetic basis of BMF

(IRB \#5024). Deep NGS HLA typing and TCR repertoires were generated after DNA extraction and genomic library preparation.

An healthy control cohort was assembled from three different populations: I) 20 healthy subjects received an NGS HLA typing at Cleveland Clinic and gave their consent to participate to this study; 310 subjects with a known 6 loci HLA genotype were selected from the Allele frequency net database (AFND, USA, San Diego population, gold-standard data classification); ${ }^{63} 630$ HLA genotypes derived from Emerson and De Witt study. ${ }^{64}$ This last source provided also the control TCR repertoire dataset. The ethnic composition of the control cohort as well as relative HED distributions are reported in supplementary appendix (Figure S10).

HLA genotypes of patients with myeloid neoplasia were obtained from the Cleveland Clinic bone marrow transplant registry. T1D dataset was built after HLA allele imputation of data generated from a single nucleotide polymorphism (SNP) array platform and was provided by the Type 1 diabetes genomic consortium (T1DGC, National Institute of Diabetes and Digestive and Kidney Diseases NIDDK). ${ }^{65,66,67}$

HLA dataset for the Finnish cohort was provided by the Hematology Research Unit Helsinki in collaboration with the Histocompability Testing Laboratory, Finnish Red Cross Blood Service (N=37 IAA patients and $\mathrm{N}=42$ healthy controls). For this cohort, HLA typing was performed with Luminex Bead Array technology complemented with sequence-specific oligonucleotide primed PCR (PCRSSO). The bead array data were interpreted according to the manufacturer's recommendations using the HLA Fusion software 3.2 (One Lambda). The rest of the control cohort was built with genotypes of Finnish individuals extracted from the 1000 Genome project $(\mathrm{N}=87){ }^{68}$

\section{DNA isolation}

Genomic DNA was isolated directly from cryopreserved unfractionated peripheral blood mononuclear cells with the Nuclei Lysis Solution (Promega) according to manufacturer's instructions.

\section{HLA sequencing, typing and SNP imputation}

A deep NGS panel (TruSight HLA v2 Illumina/Gendex) was used to provide an unambiguous phaseresolved HLA typing for IAA/PNH cohort and 20 healthy subjects from the institutional enrollment. In brief 11 HLA loci (Class I HLA-A, B, and C; Class II HLA-DRB1/3/4/5, HLA-DQA1, HLA-DQB1, HLA-DPA1, and HLA-DPB1) were amplified with a long-range polymerase chain reaction (PCR). Briefly, after 
medRxiv preprint doi: https://doi.org/10.1101/2021.05.28.21258028; this version posted June 3, 2021. The copyright holder for this preprint

(which was not certified by peer review) is the author/funder, who has granted medRxiv a license to display the preprint in perpetuity. It is made available under a CC-BY-NC-ND 4.0 International license .

Immunogenetic basis of BMF

amplification a transposone-based DNA tagmentation was applied to generate DNA amplicons, via DNA fragmentation and addition of adapter sequences. Additional PCR steps provided sequence adapters and indexing primers to generate sequencing-ready DNA libraries. Prepared libraries were then loaded directly onto a MiSeq System for sequencing.

High resolution six-digit HLA typing was then inferred with HLA-HD $\vee 1.3,69,70$ based on the nomenclature of the IPD-IMGT-HLA database v. $3.40 .{ }^{71}$ This tool previously showed its ability to provide an highly accurate HLA inference (miscall rate $<4 \%$ ) in independent studies ${ }^{72,73}$ and was crossvalidated in our cohort, for patients with available SSO-PCR HLA typing (Table S14).

SNP2HLA v.1.0 was used to impute HLA alleles and SNPs in HLA region from the genotype data provided by the T1DGC as previously described. ${ }^{74}$ For this cohort genotyping was performed using the custom high-density genotyping array Immunochip (Illumina), designed to densely genotype immune-mediated disease loci identified by common variant genome wide association studies (GWAS). With this recommended method, HLA imputation from the Immunochip platform, has been shown to have an accuracy at four-digit resolution between 0.95 and 0.99 across loci. $^{34}$ SSO-PCR methods were used to generate HLA genotypes from the myeloid neoplasia cohort in our Institution and from the Finnish cohort in the Helsinki University Hospital.

\section{Association study and allele risk analysis}

High quality 4-digit HLA data, in patient and control cohorts were used for the phenotypic association study and the risk allele analysis. First, frequency of each allele present in IAA/PNH and HC populations was computed by direct counting. The significance of associations with class assignment (phenotype status) was assessed by performing two-tailed Fisher's exact test applying hypergeometric distribution in a $2 \times 2$ contingency table. Estimated effect size (odd ratio) was calculated for each allele taking into account either allelic frequencies (additive model) or genotypic frequencies (dominant model), Tables S1 and S2.

Given a $p$-value $<0.05$, the false discovery rate (FDR) was determined based on the correction for multiple testing (q-value), according to Benjamini and Hochberg procedure. ${ }^{45}$ Alleles identified as differentially distributed between IAA/PNH and $\mathrm{HC}$ groups (q-value $<0.05$ ) with this procedure were considered for logistic regression analysis to confirm the phenotypic associations. A multivariable logistic regression analysis was applied to test the independent contribution of HED and risk allele profiles on BMF phenotype. 
medRxiv preprint doi: https://doi.org/10.1101/2021.05.28.21258028; this version posted June 3, 2021. The copyright holder for this preprint

(which was not certified by peer review) is the author/funder, who has granted medRxiv a license to display the preprint in perpetuity.

It is made available under a CC-BY-NC-ND 4.0 International license .

Immunogenetic basis of BMF

Pagliuca et al. 2021

\section{HED computation}

HED scores were computed for all the subjects and all the genotypes in study, using the algorithm published by Pierini and Lenz, applying a customized perl script (https://sourceforge.net/projects/granthamdist/) for the calculation of the amino acid sequence divergence. ${ }^{41,7}$ Briefly, starting from a dictionary including all the protein sequences of exons 2 and 3 for class I alleles and exon 2 for class II alleles, assembled from the IPD-IMGT/HLA database v.3.4071 ,we calculated HED for 6 class I (A, B, C) and II HLA loci (DRB1, DQB1, DPB1).

Means of class I and II were used as quantitative parameters for the analysis of the impact of HED on phenotypic characteristics and clinical outcomes. When appropriate, categorization of high and low intra-locus or intra-class HED was defined according to the 50th percentile of the respective metrics in healthy controls.

\section{Immunopeptidomic analysis}

We used for this analysis a HSC specific proteomic reference as published by Henrich et al. ${ }^{51}$ Amino acids sequences of all the possible alternative transcripts identified based on this protein ID list were selected from the human peptidome reference, downloaded from Ensembl ${ }^{75}$

(ftp://ftp.ensembl.org/pub/grch37/update/fasta/homo_sapiens/pep//Homo sapiens.GRCh37.pep. all.fa).

The resulting FASTA file was submitted to NetMHCIlpan $4.0^{76}$ within a high performant computational environment, in order to determine the binding predictions for selected class I and II HLA molecules for all the peptides with a percentile rank of eluted ligand prediction score $<2 \%$ for strong binders and $<10 \%$ for weak binders. This analysis was performed for all the alleles in DRB1 locus and for the most frequent DQB1/DQA1 haplotypes present in our patient and healthy control population.

\section{Crystallographic structures and molecular dynamics}

Crystallographic structures of DR molecules were prepared with the PyMOL (www.pymol.org) program using the known structure of the complex DRA*01:01-DRB1*15:01-MBP (PDB: 1 BX2, ${ }^{77}$ resolution: $2.6 \AA ̊$ ) , DRB1*14:02-DRA*01:01/ vimentin (amino acid positions: 59-71, PDB:1H1578, resolution: $3.1 \AA$ A) and DRB5*01:01-DRA*01:01/EBV DNA polymerase (628-641) (PDB:6ATF ${ }^{79}$, resolution: $1.9 \AA$ ). Homology models of DRB1*16:01 and DRB1*12:01 were constructed using the software I-TASSER, ${ }^{80,81}$ and the protein sequences of DRB1*16:01:01 and DRB1*12:01:01:01 alleles 
medRxiv preprint doi: https://doi.org/10.1101/2021.05.28.21258028; this version posted June 3, 2021. The copyright holder for this preprint

(which was not certified by peer review) is the author/funder, who has granted medRxiv a license to display the preprint in perpetuity. It is made available under a CC-BY-NC-ND 4.0 International license.

Immunogenetic basis of BMF

were extracted from the IPD-IMGT/HLA database. All model structures were superimposed to the known structure of DRB1*15:01. DRA*01:01:01:01 was used as reference for the $\alpha$ chain in the three structures. Model structures of HLA with MBP were subject to molecular dynamic (MD) simulations and analyses using the Amber18 program. ${ }^{82}$ The protocol of MDsimulations was conducted according to a previous study. ${ }^{83}$ Thirty-six ns production-run MD simulations were performed to calculate the fluctuations of the antigen MBP within the DR binding groove (as in Fig S11). Twenty conformations in the 16-36 ns MD simulations were used to calculate the total binding free energy between HLA and MBP using the MM-GBSA method. ${ }^{84}$ The TCR $\alpha$ and $\beta$ chains, DRA*01:01-DRB1*15:01 and CD4 model structure was constructed by aligning HLA/peptide with the peptide-MHC in the crystal structure of TCR, peptide-MHC, CD4 (PDB: 3TOE).

\section{TCR $\beta$ chain sequencing and analysis}

Immunosequencing of the CDR3 regions of human TCR $\beta$ chains was performed using the ImmunoSEQ Assay (Adaptive Biotechnologies, Seattle, WA), as previously described. ${ }^{85,86,87}$ In brief, extracted genomic DNA was amplified in a bias-controlled multiplex PCR, with i) a first PCR step consisting in forward and reverse amplification primers specific for every $\mathrm{V}$ and $\mathrm{J}$ gene segment, to allow the amplification of the hypervariable CDR3 region, and ii) a second PCR adding a proprietary barcode sequence and Illumina adapter sequences. CDR3 libraries were sequenced on an Illumina MiSeq system according to the manufacturer's instructions. Rearrangement details from healthy controls (HC, age-matched with donors recruited in our cohort) were derived from the Emerson and DeWitt study (data provided by the original publication and the ImmuneACCESS platform). ${ }^{64,88}$ ImmunoSeq Analizer 3.0 suite was used for sample export and preliminary statistics and quality control steps while $\mathrm{R}$ bioconductor ${ }^{89}$ environment and Immunarch $\mathrm{R}^{90}$ suite were used for all the downstream analyses (see supplementary appendix).

All metrics were calculated based only on the "productive" rearrangements (translating a functional amino acids sequence, intended as templates that were in-frame and did not contain a stop codon in their sequence) within the normalized down-sampled dataset. Details concerning the bioanalytic workflow are reported in the supplementary appendix. Sequencing results are accessible through the publicly available repository of ImmuneAccess platform.

\section{Statistical analysis}


medRxiv preprint doi: https://doi.org/10.1101/2021.05.28.21258028; this version posted June 3, 2021. The copyright holder for this preprint

(which was not certified by peer review) is the author/funder, who has granted medRxiv a license to display the preprint in perpetuity. It is made available under a CC-BY-NC-ND 4.0 International license .

Immunogenetic basis of BMF

All metrics in study were generally treated as continuous variables and categorized when needed. Median, interquartile ranges (IQR), mean and $95 \% \mathrm{Cl}$ intervals were used where appropriate. Frequency and distribution of categorical variables were expressed as percentage. For all relevant comparisons, after testing for normal distribution, comparative analyses between two groups were performed, by two-sided paired or unpaired Student's t-tests at $95 \% \mathrm{Cl}$. In the case of not normally distributed data, the wilcoxon matched-pairs signed rank test at $95 \% \mathrm{Cl}$ was used. Fisher's exact test or Chi-square were applied for independent group comparisons, in case of testing more than two groups a one-way ANOVA test was used. Correction for multiple testing was made through Benjamini and Hochberg correction. ${ }^{45}$ Cox regression and proportional hazard models for the competing risk sub distributions were used to assess the impact of HED metrics on clinical outcomes (OS, cumulative incidence of progression) in univariable setting. ${ }^{91}$ All statistical tests were two-sided, and a P-value $<0.05$ was considered statistically significant. OS was defined as the time from diagnosis to the last follow-up or death for any cause. Death at any time was used as competitive events for the cumulative incidence of progression to MDS. All of the analyses and data visualization were performed using the statistical computing environment R (4.0.0 R Core Team, R Foundation for Statistical Computing, Vienna, Austria) and excel Microsoft 365.

\section{AUTHORSHIP AND DISCLOSURES}

\section{Authorship contributions:}

SP designed the study, collected, analyzed and interpreted the data, performed the bioinformatic and statistical analyses and wrote the manuscript. CG performed NGS experiments, clinical data collection and participated in the analysis interpretation. SK, LT, MZ, AK, HA, YG, BJK helped in sample and data collection. TLa and VV edited the manuscript, helped in data interpretation and gave helpful intellectual insights during the study. YS, BJP, MN, BH actively participated in patient recruitment, management, and follow-up. SL and SM provided genotypic data for the Finnish cohort and critically revised the manuscript. CY performed the molecular modeling, analyzed the crystallographic structures helped in drafting the methods inherent to this part. TC and TLe helped in data interpretation and analytical method development. JM designed and conceptualized the study, interpreted the data analysis and edited the manuscript. First and last authors took responsibility for the integrity and the accuracy of the data presented. All authors reviewed and approved the final version of this manuscript. 
medRxiv preprint doi: https://doi.org/10.1101/2021.05.28.21258028; this version posted June 3, 2021. The copyright holder for this preprint

(which was not certified by peer review) is the author/funder, who has granted medRxiv a license to display the preprint in perpetuity.

It is made available under a CC-BY-NC-ND 4.0 International license .

Immunogenetic basis of BMF

Pagliuca et al. 2021

\section{Conflict-of-interest disclosure:}

This research was conducted in absence of any commercial or financial relationships that could be construed as a potential conflict of interest.

\section{Data sharing}

All the data that support the findings of this study are available within the Article and Supplementary Files. Genotypic and phenotypic raw data, including HLA genotypes of all the subject in study will be provided upon request to the corresponding authors. TCR sequencing data will be provided through the ImmuneACCESS platform (Adaptive Biotechnology).

\section{Acknowledgements}

This work was supported by US National Institute of Health (NIH) grants R35 HL135795, R01HL123904, R01 380HL118281, R01 HL128425, R01 HL132071, Edward P.Evans Foundation (to J.M), Italian Society of Hematology, Fondation ARC pour la Recherche sur le Cancer, Philippe Foundation, Association HPN France / Fondation maladies rares (to S.P.), The AmericanItalian Cancer Foundation (to C.G.); VeloSano Pilot Award, and Vera and Joseph Dresner FoundationMDS (to V.V.). European Research Council (M-IMM and STRATIFY projects), Academy of Finland, Sigrid Juselius Foundation, and Cancer Foundation Finland (to S.L. and S.M).

We thank Diego Chowell for his helpful insights and critical revision of the manuscript.

We thank the National Institute of Diabetes and Digestive and Kidney diseases and the Type 1 Diabetes Genetic Consortium that provided the T1DGC Immunochip/HLA Reference Panel used in this study and Dr. John Sidney and Prof. Alessandro Sette who kindly provided the ethnicity/race information for the subjects from San Diego population.

\section{References}

1. Young, N. S. \& Maciejewski, J. The pathophysiology of acquired aplastic anemia. N Engl J Med 336, 1365-1372 (1997).

2. Babushok, D. V. et al. Somatic HLA Mutations Expose the Role of Class I-Mediated Autoimmunity in Aplastic Anemia and its Clonal Complications. Blood Adv 1, 1900-1910 (2017).

3. Zaimoku, Y. et al. Identification of an HLA class I allele closely involved in the autoantigen presentation in acquired aplastic anemia. Blood 129, 2908-2916 (2017).

4. Katagiri, T. et al. Frequent loss of HLA alleles associated with copy number-neutral $6 \mathrm{pLOH}$ in 
medRxiv preprint doi: https://doi.org/10.1101/2021.05.28.21258028; this version posted June 3, 2021. The copyright holder for this preprint (which was not certified by peer review) is the author/funder, who has granted medRxiv a license to display the preprint in perpetuity. It is made available under a CC-BY-NC-ND 4.0 International license .

Immunogenetic basis of BMF

Pagliuca et al. 2021

acquired aplastic anemia. Blood 118, 6601-6609 (2011).

5. Afable, M. G. et al. SNP array-based karyotyping: differences and similarities between aplastic anemia and hypocellular myelodysplastic syndromes. Blood 117, 6876-6884 (2011).

6. Young, N. S. \& Maciejewski, J. P. Genetic and environmental effects in paroxysmal nocturnal hemoglobinuria: this little PIG-A goes 'Why? Why? Why?' J Clin Invest 106, 637-641 (2000).

7. Young, N. S. Current concepts in the pathophysiology and treatment of aplastic anemia. Hematology 2013, 76-81 (2013).

8. Risitano, A. M. Oligoclonal and polyclonal CD4 and CD8 lymphocytes in aplastic anemia and paroxysmal nocturnal hemoglobinuria measured by Vbeta CDR3 spectratyping and flow cytometry. Blood 100, 178-183 (2002).

9. Wlodarski, M. W. et al. Molecular strategies for detection and quantitation of clonal cytotoxic Tcell responses in aplastic anemia and myelodysplastic syndrome. Blood 108, 2632-2641 (2006).

10. Zeng, W., Maciejewski, J. P., Chen, G. \& Young, N. S. Limited heterogeneity of T cell receptor BV usage in aplastic anemia. J Clin Invest 108, 765-773 (2001).

11. Risitano, A. M. et al. In-vivo dominant immune responses in aplastic anaemia: molecular tracking of putatively pathogenetic T-cell clones by TCR $\beta$-CDR3 sequencing. The Lancet 364, 355-364 (2004).

12. Selleri, C., Maciejewski, J. P., Sato, T. \& Young, N. S. Interferon-gamma constitutively expressed in the stromal microenvironment of human marrow cultures mediates potent hematopoietic inhibition. Blood 87, 4149-4157 (1996).

13. Sloand, E. Intracellular interferon-gamma in circulating and marrow T cells detected by flow cytometry and the response to immunosuppressive therapy in patients with aplastic anemia. Blood 100, 1185-1191 (2002).

14. Maciejewski, J., Selleri, C., Anderson, S. \& Young, N. S. Fas antigen expression on CD34+ human marrow cells is induced by interferon gamma and tumor necrosis factor alpha and potentiates cytokine-mediated hematopoietic suppression in vitro. Blood 85, 3183-3190 (1995).

15. Nisticò, A. \& Young, N. S. gamma-Interferon gene expression in the bone marrow of patients with aplastic anemia. Ann Intern Med 120, 463-469 (1994).

16. Zoumbos, N. C., Gascón, P., Djeu, J. Y., Trost, S. R. \& Young, N. S. Circulating Activated Suppressor T Lymphocytes in Aplastic Anemia. New England Journal of Medicine 312, 257-265 (1985).

17. de Latour, R. P. et al. Th17 immune responses contribute to the pathophysiology of aplastic anemia. Blood 116, 4175-4184 (2010).

18. Kordasti, S. et al. Functional characterization of CD4+ T cells in aplastic anemia. Blood 119, 2033-2043 (2012).

19. Kordasti, S. et al. Deep phenotyping of Tregs identifies an immune signature for idiopathic aplastic anemia and predicts response to treatment. Blood 128, 1193-1205 (2016).

20. Luzzatto, L., Bessler, M. \& Rotoli, B. Somatic Mutations in Paroxysmal Nocturnal Hemoglobinuria: A Blessing in Disguise? Cell 88, 1-4 (1997).

21. Katagiri, T. et al. Frequent loss of HLA alleles associated with copy number-neutral $6 \mathrm{pLOH}$ in acquired aplastic anemia. Blood 118, 6601-6609 (2011).

22. Kikkawa, E. et al. Detection of $6 \mathrm{pLOH}$ in an aplastic anemia patient by in phase HLA genotyping. HLA 95, 465-469 (2020).

23. Imi, T. et al. Sustained clonal hematopoiesis by HLA-lacking hematopoietic stem cells without driver mutations in aplastic anemia. Blood Adv 2, 1000-1012 (2018).

24. Mizumaki, $H$. et al. A frequent nonsense mutation in exon 1 across certain HLA-A and -B alleles in leukocytes of patients with acquired aplastic anemia. Haematologica (2020) doi:10.3324/haematol.2020.247809.

25. Savage, S. A. et al. Genome-wide Association Study Identifies HLA-DPB1 as a Significant Risk Factor for Severe Aplastic Anemia. Am J Hum Genet 106, 264-271 (2020). 
medRxiv preprint doi: https://doi.org/10.1101/2021.05.28.21258028; this version posted June 3, 2021. The copyright holder for this preprint (which was not certified by peer review) is the author/funder, who has granted medRxiv a license to display the preprint in perpetuity. It is made available under a CC-BY-NC-ND 4.0 International license .

Immunogenetic basis of BMF

26. Saunthararajah, Y. et al. HLA-DR15 (DR2) is overrepresented in myelodysplastic syndrome and aplastic anemia and predicts a response to immunosuppression in myelodysplastic syndrome. Blood 100, 1570-1574 (2002).

27. Maciejewski, J. P. et al. Increased frequency of HLA-DR2 in patients with paroxysmal nocturnal hemoglobinuria and the PNH/aplastic anemia syndrome. Blood 98, 3513-3519 (2001).

28. Dhaliwal, J. S., Wong, L., Kamaluddin, M. A., Yin, L. Y. \& Murad, S. Susceptibility to aplastic anemia is associated with HLA-DRB1*1501 in an aboriginal population in Sabah, Malaysia. Hum Immunol 72, 889-892 (2011).

29. Oguz, F. S. et al. HLA-DRB1*15 and pediatric aplastic anemia. Haematologica 87, 772-774 (2002).

30. Song, E. Y., Park, S., Lee, D. S., Cho, H. I. \& Park, M. H. Association of human leukocyte antigen-DRB1 alleles with disease susceptibility and severity of aplastic anemia in Korean patients. Hum Immunol 69, 354-359 (2008).

31. Yari, F. et al. Association of aplastic anaemia and Fanconi's disease with HLA-DRB1 alleles. Int J Immunogenet 35, 453-456 (2008).

32. Nakao, S. et al. Response to immunosuppressive therapy and an HLA-DRB1 allele in patients with aplastic anaemia: HLA-DRB1*1501 does not predict response to antithymocyte globulin. $\mathrm{Br} J$ Haematol 92, 155-158 (1996).

33. Nakao, S. et al. Identification of a specific HLA class II haplotype strongly associated with susceptibility to cyclosporine-dependent aplastic anemia. Blood 84, 4257-4261 (1994).

34. Moutsianas, L. et al. Class II HLA interactions modulate genetic risk for multiple sclerosis. Nat Genet 47, 1107-1113 (2015).

35. Varney, M. D. et al. HLA DPA1, DPB1 alleles and haplotypes contribute to the risk associated with type 1 diabetes: analysis of the type 1 diabetes genetics consortium families. Diabetes 59, 20552062 (2010).

36. Chinniah, R. et al. Association of HLA class II alleles/haplotypes and amino acid variations in the peptide binding pockets with rheumatoid arthritis. Int J Rheum Dis 22, 1553-1562 (2019).

37. Wang, C. et al. Genome-wide Association Studies of Specific Antinuclear Autoantibody Subphenotypes in Primary Biliary Cholangitis. Hepatology 70, 294-307 (2019).

38. Kular, L. et al. DNA methylation as a mediator of HLA-DRB1*15:01 and a protective variant in multiple sclerosis. Nat Commun 9, 2397 (2018).

39. Grantham, R. Amino Acid Difference Formula to Help Explain Protein Evolution. Science 185, 862-864 (1974).

40. Chowell, D. et al. Evolutionary divergence of HLA class I genotype impacts efficacy of cancer immunotherapy. Nature Medicine 25, 1715-1720 (2019).

41. Pierini, F. \& Lenz, T. L. Divergent Allele Advantage at Human MHC Genes: Signatures of Past and Ongoing Selection. Molecular Biology and Evolution 35, 2145-2158 (2018).

42. Krishna, C., Chowell, D., Gönen, M., Elhanati, Y. \& Chan, T. A. Genetic and environmental determinants of human TCR repertoire diversity. Immun Ageing 17, 26 (2020).

43. Arora, J. et al. HIV peptidome-wide association study reveals patient-specific epitope repertoires associated with HIV control. Proc Natl Acad Sci U S A 116, 944-949 (2019).

44. Arora, J. et al. HLA Heterozygote Advantage against HIV-1 Is Driven by Quantitative and Qualitative Differences in HLA Allele-Specific Peptide Presentation. Mol Biol Evol 37, 639-650 (2020). 45. Benjamini, Yoav; Hochberg, Yosef. Controlling the false discovery rate: a practical and powerful approach to multiple testing. J. Roy. Statist. Soc. Ser. B 57 (1995), no. 1, 289-300.

46. Dorak, M. T. et al. Conserved extended haplotypes of the major histocompatibility complex: further characterization. Genes Immun 7, 450-467 (2006).

47. Erlich, H. et al. HLA DR-DQ haplotypes and genotypes and type 1 diabetes risk: analysis of the type 1 diabetes genetics consortium families. Diabetes 57, 1084-1092 (2008). 
medRxiv preprint doi: https://doi.org/10.1101/2021.05.28.21258028; this version posted June 3, 2021. The copyright holder for this preprint (which was not certified by peer review) is the author/funder, who has granted medRxiv a license to display the preprint in perpetuity. It is made available under a CC-BY-NC-ND 4.0 International license .

Immunogenetic basis of BMF

48. Lenz, T. L. et al. Widespread non-additive and interaction effects within HLA loci modulate the risk of autoimmune diseases. Nat Genet 47, 1085-1090 (2015).

49. $\mathrm{Hu}, \mathrm{X}$. et al. Additive and interaction effects at three amino acid positions in HLA-DQ and HLA-DR molecules drive type 1 diabetes risk. Nat Genet 47, 898-905 (2015).

50. Yin, Y., Wang, X. X. \& Mariuzza, R. A. Crystal structure of a complete ternary complex of Tcell receptor, peptide-MHC, and CD4. Proc Natl Acad Sci U S A 109, 5405-5410 (2012).

51. Hennrich, M. L. et al. Cell-specific proteome analyses of human bone marrow reveal molecular features of age-dependent functional decline. Nat Commun 9, 4004 (2018).

52. Potts, W. K. \& Wakeland, E. K. Evolution of diversity at the major histocompatibility complex. Trends in Ecology \& Evolution 5, 181-187 (1990).

53. Wakeland, E. K. et al. Ancestral polymorphisms of MHC class II genes: Divergent allele advantage. Immunol Res 9, 115-122 (1990).

54. Pierini, F. \& Lenz, T. L. Divergent Allele Advantage at Human MHC Genes: Signatures of Past and Ongoing Selection. Mol Biol Evol 35, 2145-2158 (2018).

55. Sugimori, C. et al. Roles of DRB1 *1501 and DRB1 *1502 in the pathogenesis of aplastic anemia. Exp Hematol 35, 13-20 (2007).

56. Zdimerova, H. et al. Attenuated immune control of Epstein-Barr virus in humanized mice is associated with the multiple sclerosis risk factor HLA-DR15. Eur. J. Immunol. 51, 64-75 (2021).

57. Angelini, D. F. et al. Increased CD8+ T cell response to Epstein-Barr virus lytic antigens in the active phase of multiple sclerosis. PLoS Pathog 9, e1003220 (2013).

58. Olsson, T. Epstein Barr virus infection and immune defense related to HLA-DR15: consequences for multiple sclerosis. Eur. J. Immunol. 51, 56-59 (2021).

59. Tengvall, K. et al. Molecular mimicry between Anoctamin 2 and Epstein-Barr virus nuclear antigen 1 associates with multiple sclerosis risk. Proc Natl Acad Sci U S A 116, 16955-16960 (2019).

60. Brightman, S. E., Naradikian, M. S., Miller, A. M. \& Schoenberger, S. P. Harnessing neoantigen specific CD4 T cells for cancer immunotherapy. J Leukoc Biol 107, 625-633 (2020).

61. Marty Pyke, R. et al. Evolutionary Pressure against MHC Class II Binding Cancer Mutations. Cell 175, 416-428.e13 (2018).

62. Haabeth, O. A. W. et al. How Do CD4(+) T Cells Detect and Eliminate Tumor Cells That Either Lack or Express MHC Class II Molecules? Front Immunol 5, 174 (2014).

63. Gonzalez-Galarza, F. F. et al. Allele frequency net database (AFND) 2020 update: goldstandard data classification, open access genotype data and new query tools. Nucleic Acids Res 48, D783-D788 (2020).

64. Emerson, R. O. et al. Immunosequencing identifies signatures of cytomegalovirus exposure history and HLA-mediated effects on the T cell repertoire. Nat Genet 49, 659-665 (2017).

65. Bradfield, J. P. et al. A genome-wide meta-analysis of six type 1 diabetes cohorts identifies multiple associated loci. PLoS Genet 7, e1002293 (2011).

66. Hilner, J. E. et al. Designing and implementing sample and data collection for an international genetics study: the Type 1 Diabetes Genetics Consortium (T1DGC). Clin Trials 7, S5-S32 (2010).

67. Onengut-Gumuscu, S. et al. Fine mapping of type 1 diabetes susceptibility loci and evidence for colocalization of causal variants with lymphoid gene enhancers. Nat Genet 47, 381-386 (2015).

68. The 1000 Genomes Project Consortium. A global reference for human genetic variation. Nature 526, 68-74 (2015).

69. Kawaguchi, S. \& Matsuda, F. High-Definition Genomic Analysis of HLA Genes Via Comprehensive HLA Allele Genotyping. in Immunoinformatics (ed. Tomar, N.) vol. 2131 31-38 (Springer US, 2020).

70. Kawaguchi, S., Higasa, K., Shimizu, M., Yamada, R. \& Matsuda, F. HLA-HD: An accurate HLA typing algorithm for next-generation sequencing data. Human Mutation 38, 788-797 (2017). 
medRxiv preprint doi: https://doi.org/10.1101/2021.05.28.21258028; this version posted June 3, 2021. The copyright holder for this preprint (which was not certified by peer review) is the author/funder, who has granted medRxiv a license to display the preprint in perpetuity. It is made available under a CC-BY-NC-ND 4.0 International license .

Immunogenetic basis of BMF

Pagliuca et al. 2021

71. Robinson, J. et al. IPD-IMGT/HLA Database. Nucleic Acids Research gkz950 (2019) doi:10.1093/nar/gkz950.

72. Li, X. et al. Benchmarking HLA genotyping and clarifying HLA impact on survival in tumor immunotherapy. Mol Oncol 1878-0261.12895 (2021) doi:10.1002/1878-0261.12895.

73. Kishikawa, T. et al. Empirical evaluation of variant calling accuracy using ultra-deep wholegenome sequencing data. Sci Rep 9, 1784 (2019).

74. Jia, X. et al. Imputing Amino Acid Polymorphisms in Human Leukocyte Antigens. PLoS ONE 8, e64683 (2013).

75. Zerbino, D. R. et al. Ensembl 2018. Nucleic Acids Research 46, D754-D761 (2018).

76. Reynisson, B. et al. Improved Prediction of MHC II Antigen Presentation through Integration and Motif Deconvolution of Mass Spectrometry MHC Eluted Ligand Data. J. Proteome Res. 19, 23042315 (2020).

77. Smith, K. J., Pyrdol, J., Gauthier, L., Wiley, D. C. \& Wucherpfennig, K. W. Crystal Structure of HLA-DR2 (DRA*0101, DRB1*1501) Complexed with a Peptide from Human Myelin Basic Protein. Journal of Experimental Medicine 188, 1511-1520 (1998).

78. Lang, H. L. E. et al. A functional and structural basis for TCR cross-reactivity in multiple sclerosis. Nat Immunol 3, 940-943 (2002).

79. Scally, S. W. et al. Molecular basis for increased susceptibility of Indigenous North Americans to seropositive rheumatoid arthritis. Ann Rheum Dis 76, 1915-1923 (2017).

80. Roy, A., Kucukural, A. \& Zhang, Y. I-TASSER: a unified platform for automated protein structure and function prediction. Nat Protoc 5, 725-738 (2010).

81. Yang, J. \& Zhang, Y. I-TASSER server: new development for protein structure and function predictions. Nucleic Acids Res 43, W174-181 (2015).

82. Case, D. A.; Ben-Shalom, I. Y.; Brozell, S. R.; Cerutti, D. S.; T.E. Cheatham, I.; Cruzeiro, V. W. D.; Darden, T. A.; Duke, R. E.; Ghoreishi, D.; Gilson, M. K.; Gohlke, H.; Goetz, A. W.; Greene, D.; Harris, R.; Homeyer, N.; Izadi, S.; Kovalenko, A.; Kurtzman, T.; Lee, T. S.; LeGrand, S.; Li, P.; Lin, C.; Liu, J.; Luchko, T.; Luo, R.; Mermelstein, D. J.; Merz, K. M.; Miao, Y.; Monard, G.; Nguyen, C.; Nguyen, H.; Omelyan, I.; Onufriev, A.; Pan, F.; Qi, R.; Roe, D. R.; Roitberg, A.; Sagui, C.; Schott-Verdugo, S.; Shen, J.; Simmerling, C. L.; Smith, J.; Salomon-Ferrer, R.; Swails, J.; Walker, R. C.; Wang, J.; Wei, H.; Wolf, R. M.; Wu, X.; Xiao, L.; York, D. M.; Kollman, P. A. AMBER 2018.

83. Yang, C.-Y. Comparative Analyses of the Conformational Dynamics Between the Soluble and Membrane-Bound Cytokine Receptors. Sci Rep 10, 7399 (2020).

84. Kollman, P. A. et al. Calculating Structures and Free Energies of Complex Molecules: Combining Molecular Mechanics and Continuum Models. Acc. Chem. Res. 33, 889-897 (2000).

85. Robins, H. S. et al. Comprehensive assessment of T-cell receptor beta-chain diversity in alphabeta T cells. Blood 114, 4099-4107 (2009).

86. Robins, H. et al. Ultra-sensitive detection of rare T cell clones. Journal of Immunological Methods 375, 14-19 (2012).

87. Carlson, C. S. et al. Using synthetic templates to design an unbiased multiplex PCR assay. Nature Communications 4, (2013).

88. Dean, J. et al. Annotation of pseudogenic gene segments by massively parallel sequencing of rearranged lymphocyte receptor loci. Genome Medicine 7, 123 (2015).

89. Gentleman, R. Bioinformatics and computational biology solutions using $R$ and Bioconductor. (Springer Science+Business Media, 2005).

90. Nazarov, V., Immunarch.Bot \& Rumynskiy, E. immunomind/immunarch: 0.6.5: Basic singlecell support. (Zenodo, 2020). doi:10.5281/ZENODO.3367200.

91. Fine, J. P. \& Gray, R. J. A Proportional Hazards Model for the Subdistribution of a Competing Risk. Journal of the American Statistical Association 94, 496-509 (1999). 


\section{Immunogenetic basis of BMF}

Figure 1

A

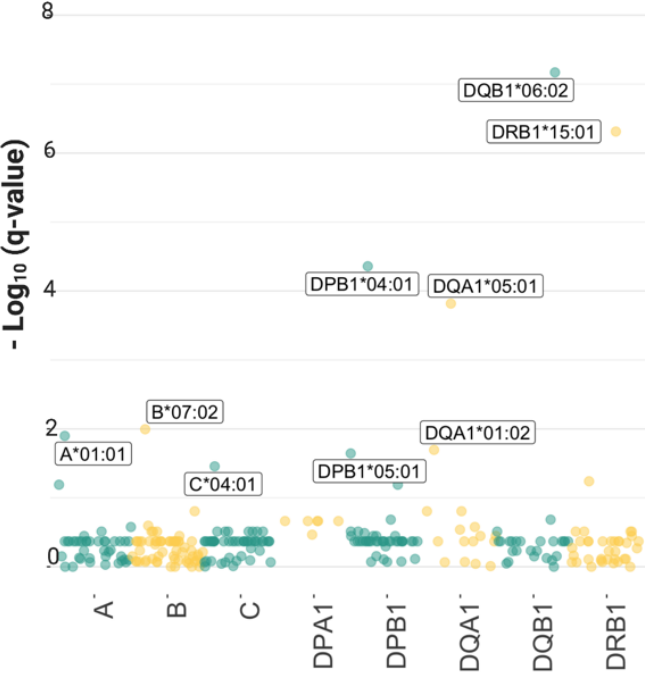

B

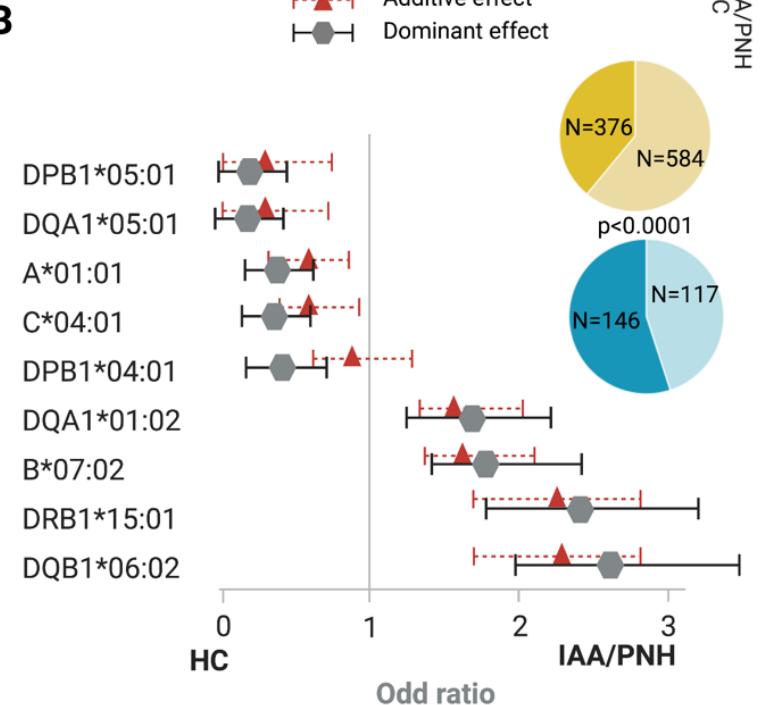

D

\section{Subset}

IAA responders

$\mid A A>20 y$

IAA with PNH clone

IAA>20y with PNH clone and responders

\section{DRB1*15:01}

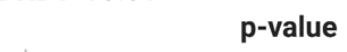


medRxiv preprint doi: https://doi.org/10.1101/2021.05.28.21258028; this version posted June 3, 2021. The copyright holder for this preprint (which was not certified by peer review) is the author/funder, who has granted medRxiv a license to display the preprint in perpetuity. It is made available under a CC-BY-NC-ND 4.0 International license .

Immunogenetic basis of BMF

Pagliuca et al. 2021

2

3

4

5

6

Figure 1: Risk allele profile analysis in idiopathic aplastic anemia and paroxysmal nocturnal hemoglobinuria patients

Abbreviations: HED: HLA Evolutionary divergence; MN: myeloid neoplasia; IAA: Idiopathic aplastic anemia; PNH: paroxysmal nocturnal hemoglobinuria; ns: non-significant.

A) Scatterplot representing the negative logarithm base 10 of the adjusted $p$-values ( $q$ value, Benjamini and Hochberg correction) resulting from the allele association analysis (see methods). Alleles with significantly different genotypic distributions are labeled according to a dominant genetic model.

B) Forest plot reporting the odd ratios (OR) defining estimated effect size of alleles enriched in healthy controls (protective) or in patients (risk). Gray markers describe OR resulting from the analysis of genotypic frequencies (dominant model); red triangles depict the OR deriving from analysis of allelic frequencies (additive model). The pie charts illustrate the distributions of subjects with at least 1 risk allele (darkest colors) or without any risk allele (brighter colors).

C) Barplot depicting the distribution of heterozygous (darkest) and homozygous (brighter) for the 4 risk alleles in controls and patients. Two-sided Fisher test is applied to test the significance of associations with phenotype.

D) Forest plots showing the results of the binomial logistic regression analysis predicting the likelihood of each risk allele association with an aplastic anemia "immuneenriched" phenotype. HC cohort ( $\mathrm{N}=960)$ was used as comparator group. All $(\mathrm{N}=263)$; IAA Responders ( $N=140)$; IAA $>20$ y ( $N=216)$; IAA with PNH clones ( $N=135)$; IAA $>20$ y with $P N H$ clone and Responders ( $\mathrm{N}=59)$. 
Figure 2

\section{$\square$ Fully heterozygous}

A Homozygous

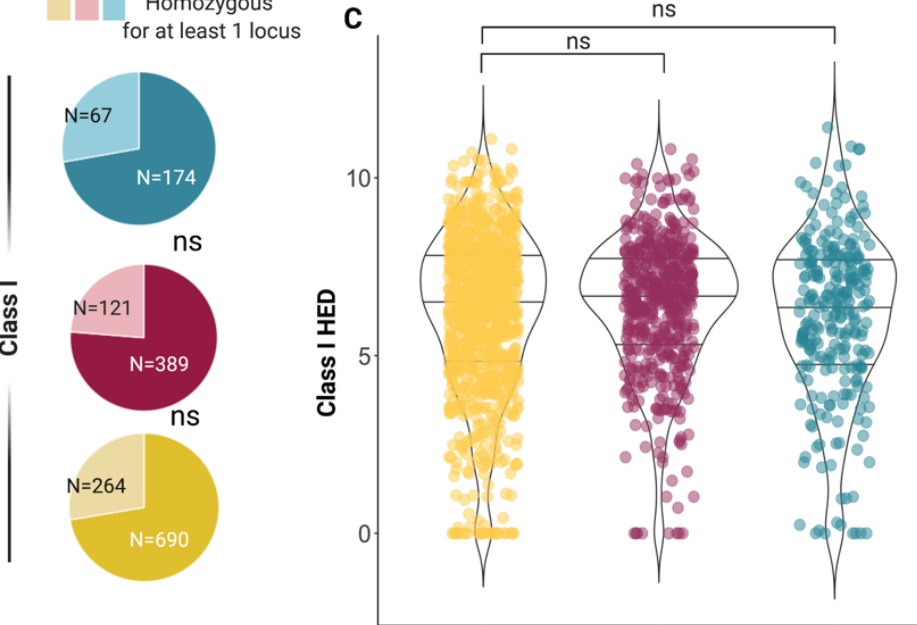

B
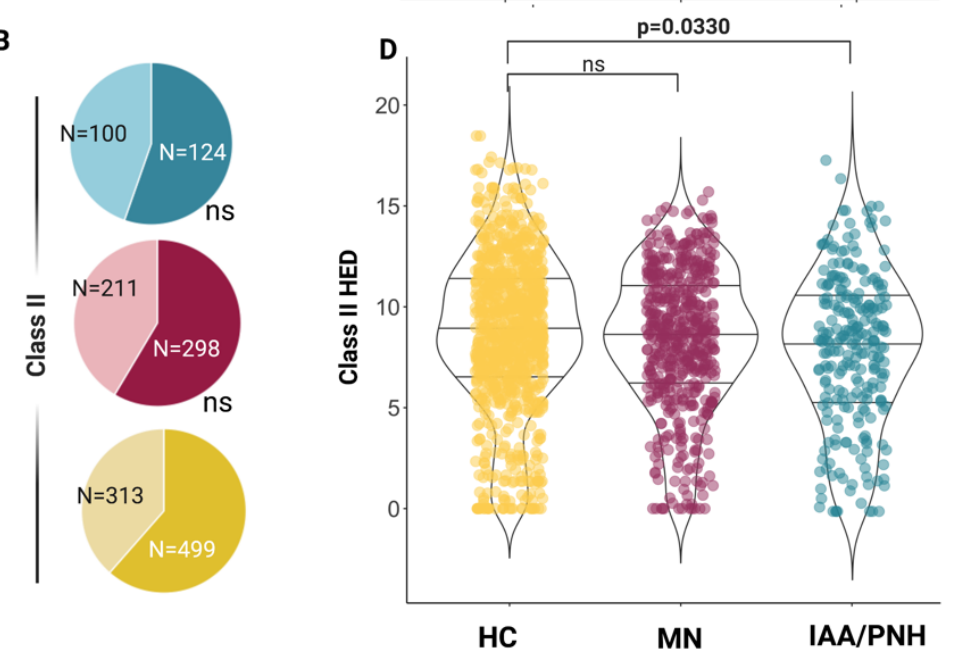
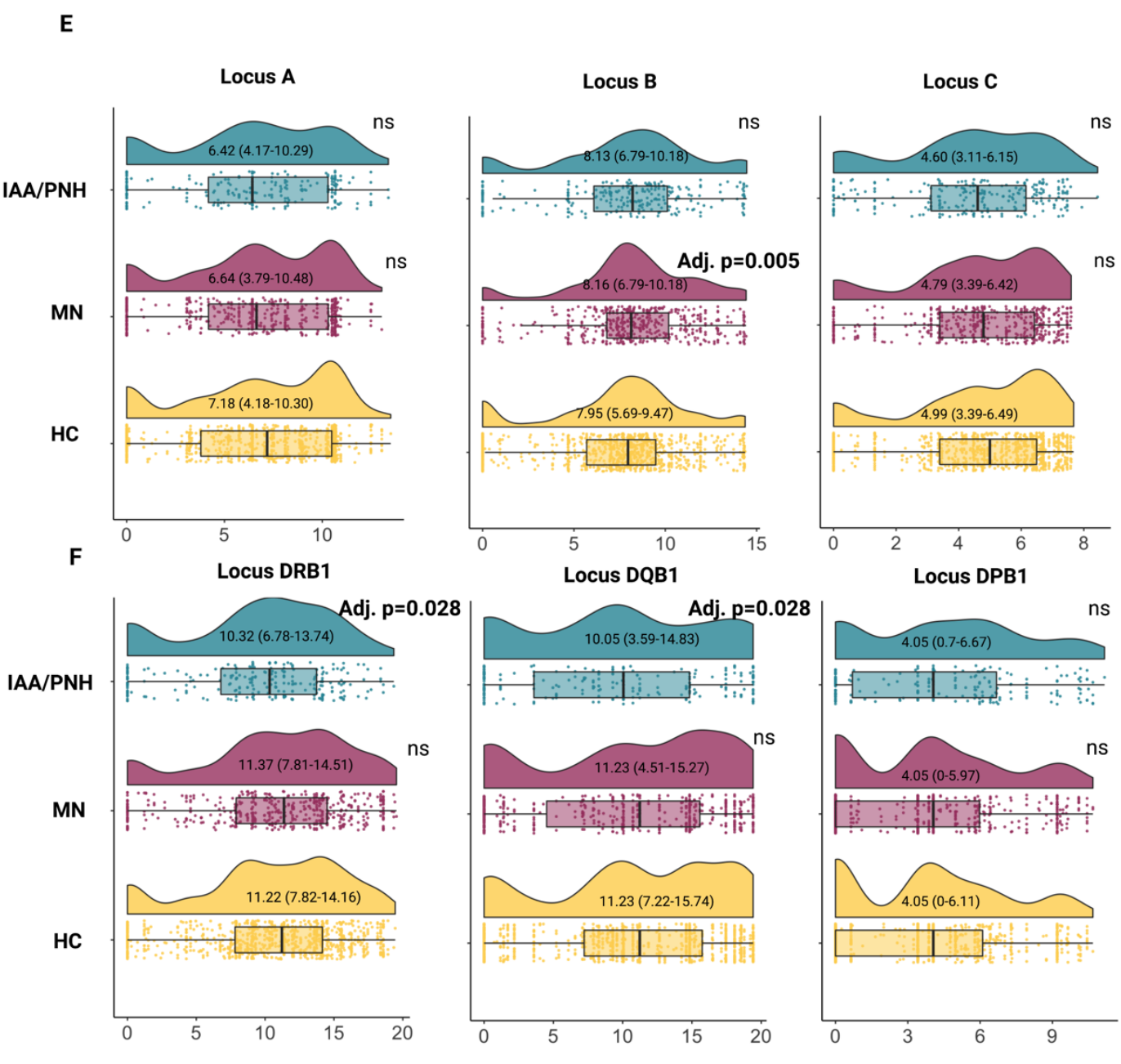
medRxiv preprint doi: https://doi.org/10.1101/2021.05.28.21258028; this version posted June 3, 2021. The copyright holder for this preprint (which was not certified by peer review) is the author/funder, who has granted medRxiv a license to display the preprint in perpetuity. It is made available under a CC-BY-NC-ND 4.0 International license.

Figure 2: Distribution of evolutionary divergence HLA genotypes in case and control cohorts

Abbreviations: HED: HLA Evolutionary divergence; MN: myeloid neoplasia; IAA: Idiopathic aplastic anemia; PNH: paroxysmal nocturnal hemoglobinuria; ns: non-significant.

A) Pie charts representing the distribution of individuals fully heterozygous or homozygous for at least one allele for class I HLA genotypes (yellow: healthy controls; purple: myeloid neoplasia; blue: idiopathic bone marrow failures). Pairwise comparisons with healthy control group; two-tailed Fisher exact test.

B) Pie charts representing the distribution of individuals fully heterozygous or homozygous for at least one allele for class IIB HLA genotypes. Pairwise comparisons with HC group; two-tailed Fisher exact test.

C) Violin-plot representing the distribution of mean class I HED scores. Each dot denotes the mean value per individual. Wilcoxon signed rank test, comparing each cohort with healthy controls.

D) Violin-plot representing the distribution of mean class II HED scores. Each dot denotes the mean value per individual. Wilcoxon signed rank test is used to calculate the $p$-value. Each cohort is compared with healthy controls.

E) Raincloud plots showing the distribution of the HED scores for each class I locus. Each graph is composed by i) a density plot representing the distribution of the metric, ii) a horizontal boxplot showing the median, the interquartile and the overall ranges of HED scores and iii) and a scatter distribution capturing the number of individuals profiled for the given locus and each HED value. Median and IQR are reported in each density plot. Wilcoxon signed rank test is used to calculate the p-value. Multitest-adjustment according to the Benjamini and Hochberg correction is computed and significativity is showed as adjusted p-value. HED scores of each cohort were compared with healthy controls.

F) Raincloud plots showing the distribution of the HED scores for each class II locus, as for E. 
Figure 3

A

Subset
All
IAA responders
IAA with PNH clone
IAA>20y with PNH
clone and responders

HED DRB1 locus

p-value

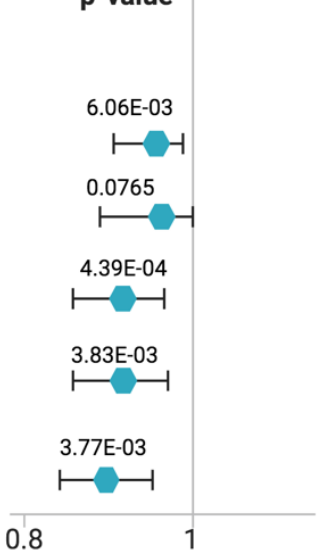

HED DQB1 locus

p-value

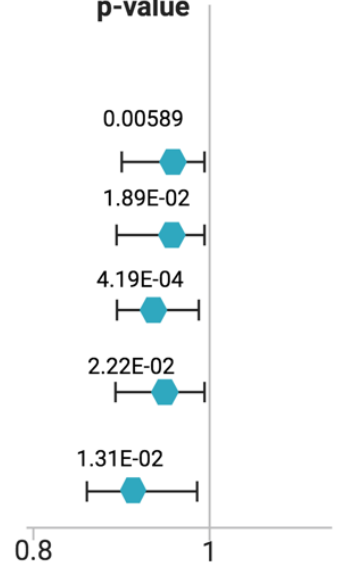

B

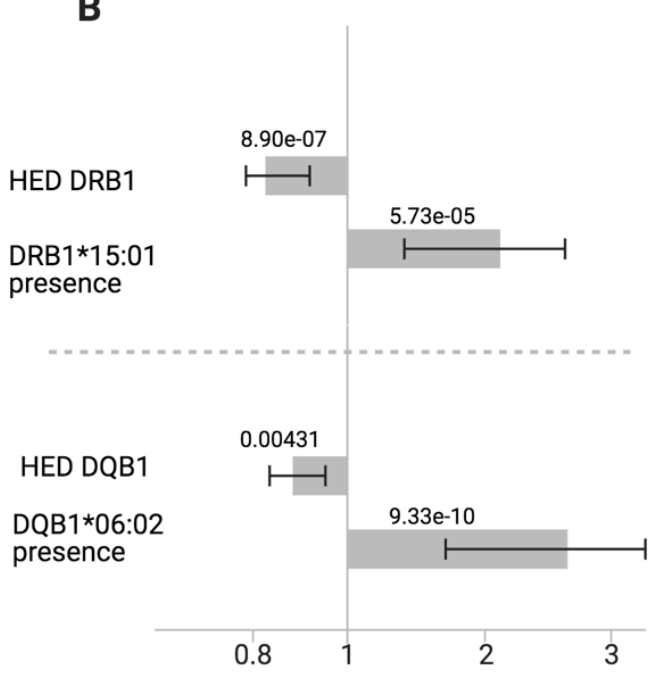

Odd ratio disease phenotype

DRB1*15:01 Non Carriers

C

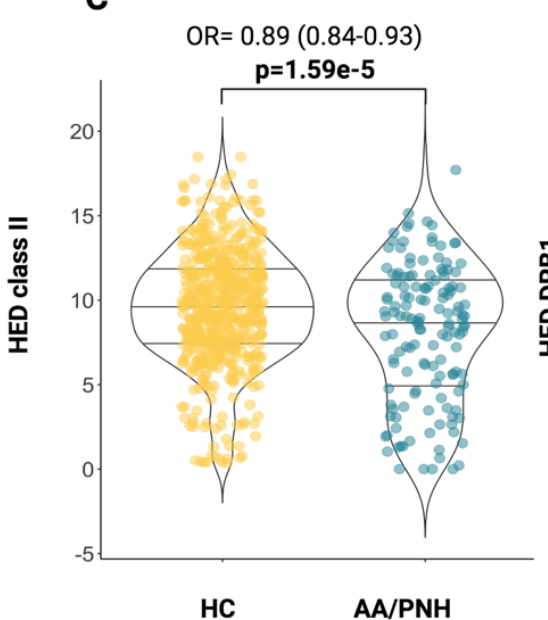

D

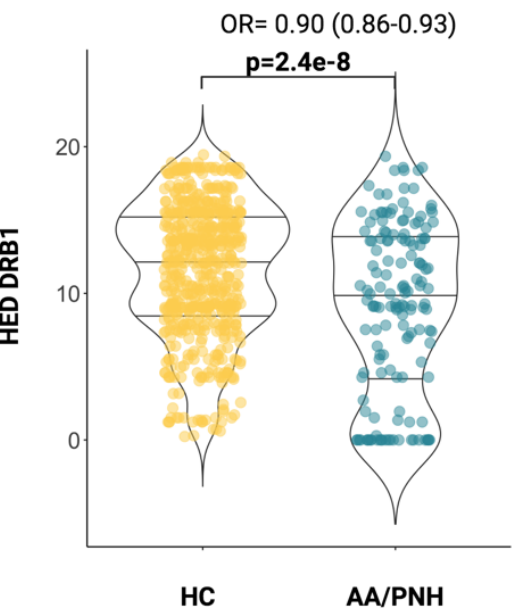

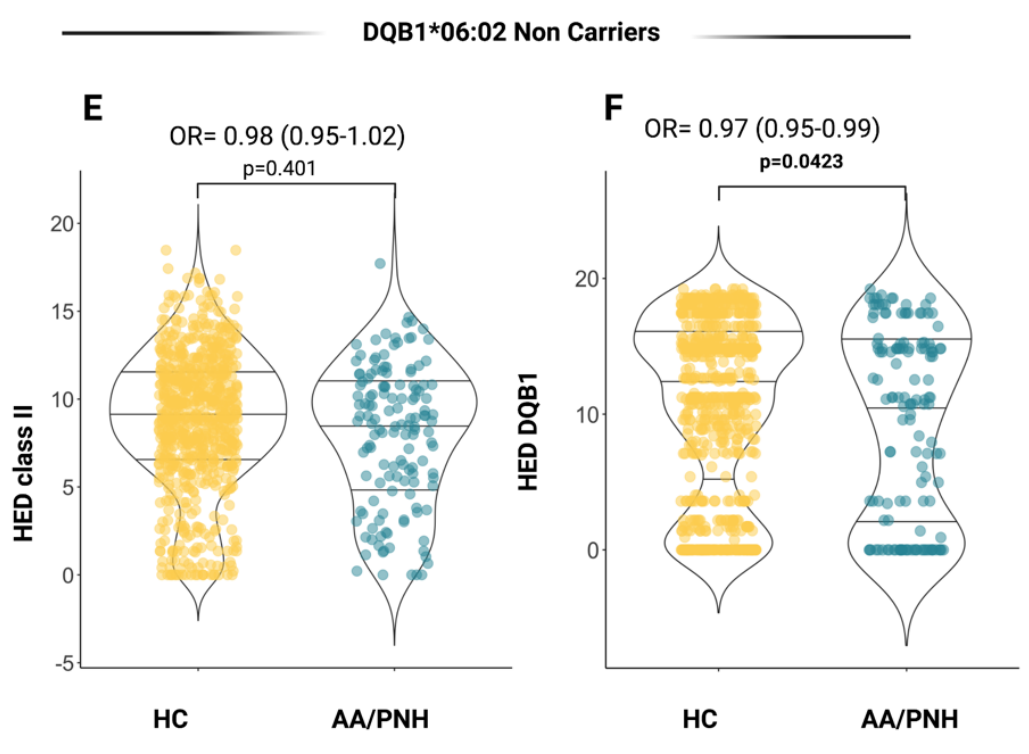


medRxiv preprint doi: https://doi.org/10.1101/2021.05.28.21258028; this version posted June 3, 2021. The copyright holder for this preprint

(which was not certified by peer review) is the author/funder, who has granted medRxiv a license to display the preprint in perpetuity.

It is made available under a CC-BY-NC-ND 4.0 International license.

Immunogenetic basis of BMF

Pagliuca et al. 2021

67

68

69

70

71

72

73

74

75

76

77

78

79

80

81

82

83

84

85

86

87

88

89

90

91

92

93

94

95

96

97

98

99

100

101

102

103

Figure 3: Binomial logistic regression analysis predicting the association between class II HED scores and aplastic anemia phenotypes

Abbreviations: HED: HLA Evolutionary divergence; IAA: Idiopathic aplastic anemia; PNH: paroxysmal nocturnal hemoglobinuria; $\mathrm{HC}$ : healthy controls

A) Forest plots showing the results of the binomial logistic regression analysis predicting the likelihood of class II and locus specific HED scores of being associated with an aplastic anemia "immune-enriched" phenotype. All ( $N=263)$; IAA Responders ( $N=140)$; IAA>20 y ( $N=216) ;$ IAA with $\mathrm{PNH}$ clones $(\mathrm{N}=135)$; IAA $>20$ y with $\mathrm{PNH}$ clone and Responders $(\mathrm{N}=59)$.

B) Multivariable logistic regression analysis testing the independent effect of HED and risk alleles on idiopathic bone marrow failure phenotype. The length of the bars indicates the odd ratio, the error bars show the $95 \%$ confident intervals, the numbers on the bars depict the $p$-values resulting from the likelihood ratio test. Two distinct models are built for DRB1 and DQB1 locus.

C) Violin plots representing the mean class II HED distribution across healthy controls and aplastic anemia patients not carrying DRB1*15:01. Wilcoxon signed rank test was used to calculate the $p$-value.

D) Violin plots representing the DRB1 HED distribution across healthy controls and aplastic anemia patients not carrying DRB1*15:01. Wilcoxon signed rank test was used to calculate the $p$-value.

E) Violin plots representing the mean class II HED distribution across healthy controls and aplastic anemia patients not carrying DQB1*06:02. Wilcoxon signed rank test was used to calculate the $p$-value.

F) Violin plots representing the DQB1 HED distribution across healthy controls and aplastic anemia patients not carrying DQB1*06:02. Wilcoxon signed rank test was used to calculate the $p$-value. 
Figure 4

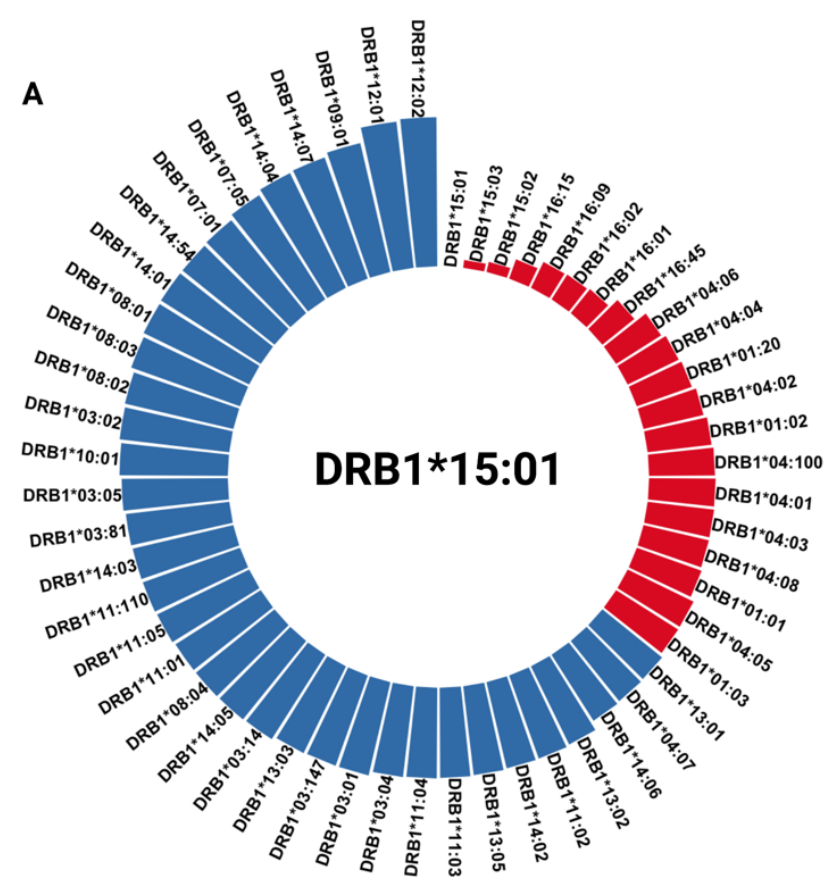

B
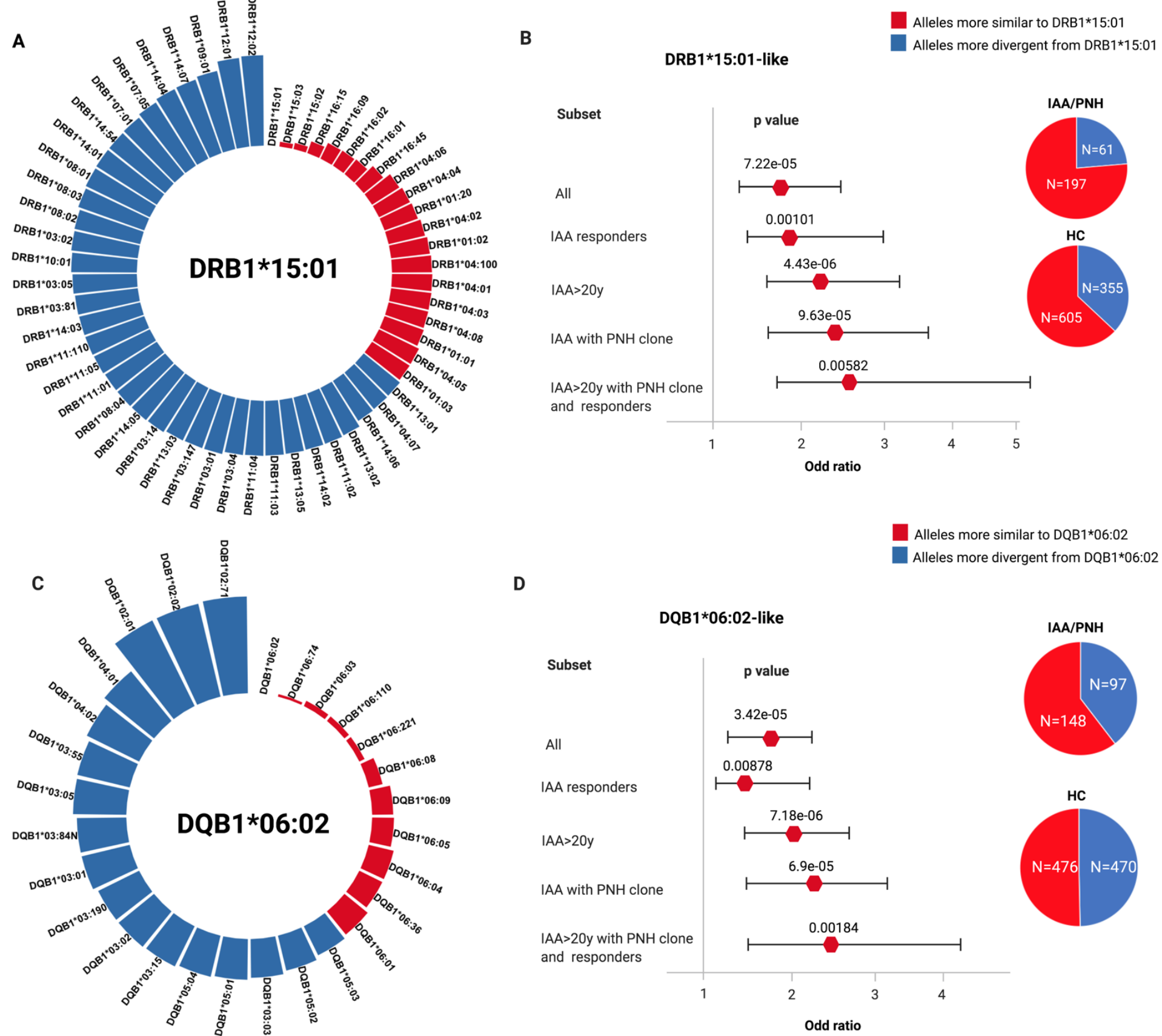

D

Alleles more similar to DQB1*06:02

Alleles more divergent from DQB1*06:02

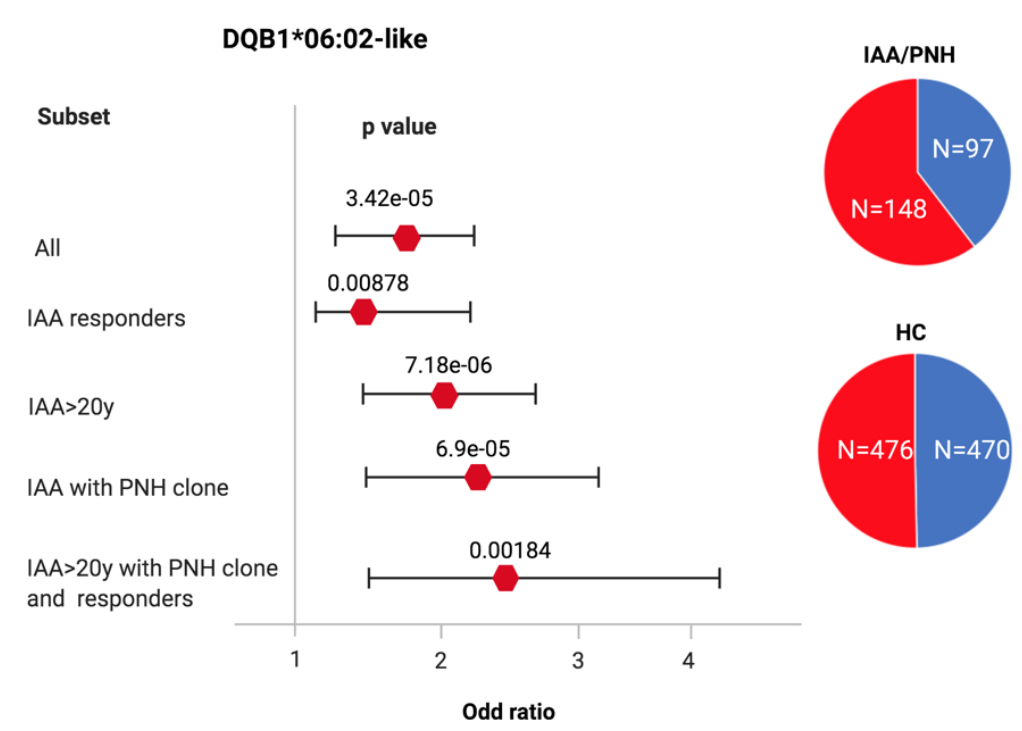


medRxiv preprint doi: https://doi.org/10.1101/2021.05.28.21258028; this version posted June 3, 2021. The copyright holder for this preprint

(which was not certified by peer review) is the author/funder, who has granted medRxiv a license to display the preprint in perpetuity.

It is made available under a CC-BY-NC-ND 4.0 International license .

Immunogenetic basis of BMF

Pagliuca et al. 2021

Figure 4: Simulated structural divergence between each class II risk allele and the pool of alleles present in DRB1 and DQB1 loci in patients and controls.

Abbreviations: HED: HLA Evolutionary divergence; IAA: Idiopathic aplastic anemia; PNH: paroxysmal nocturnal hemoglobinuria; HC: healthy controls

A) Circle graph representing the simulated divergences between DRB1*15:01 and each allele present in DRB1 locus of IAA/PNH patients and HC. Red bars illustrate the alleles more similar to DRB1*15:01 (divergent pairs located under the 25th percentile cutoff of the simulated distribution).

B) Forest plots showing the results of the binomial logistic regression analysis predicting the association between the presence of DRB1*15:01-like alleles and aplastic anemia "immune-enriched" phenotypes. $\mathrm{HCs}(\mathrm{N}=960)$ were used as comparator group. Pie charts describe the distribution of alleles more similar and more divergent from DRB1*15:01 in patients and controls. All ( $N=263)$; IAA Responders ( $N=140) ; \mid A A>20$ y $(N=216) ; I A A$ with PNH clones $(N=135) ; \mid A A>20$ y with $P N H$ clone and Responders ( $\mathrm{N}=59)$.

C) Circle graph representing the simulated divergences between DQB1*06:02 and each allele present in DQB1 locus of IAA/PNH patients and HC. Red bars illustrate the alleles more similar to DQB1*06:02 (divergent pairs located under the 25th percentile cutoff of the simulated distribution). IAA $>20$ y $(N=216) ;$ IAA with PNH clones ( $N=135) ;$ IAA $>20$ y with $P N H$ clone and Responders $(N=59)$.

D) Forest plots showing the results of the binomial logistic regression analysis predicting the association between the presence of DQB1*06:02-like alleles and an aplastic anemia "immuneenriched" phenotype. $\mathrm{HCs}(\mathrm{N}=960)$ were used as comparator group. Pie charts describe the distribution of alleles more similar and more divergent from DQB1*06:02 in patients and controls. 
medRxiv preprint doi: https://doi.org/10.1101/2021.05.28.21258028; this version posted June 3, 2021. The copyright holder for this preprint (which was not certified by peer review) is the author/funder, who has granted medRxiv a license to display the preprint in perpetuity. It is made available under a CC-BY-NC-ND 4.0 International license.

Immunogenetic basis of BMF

Figure 5
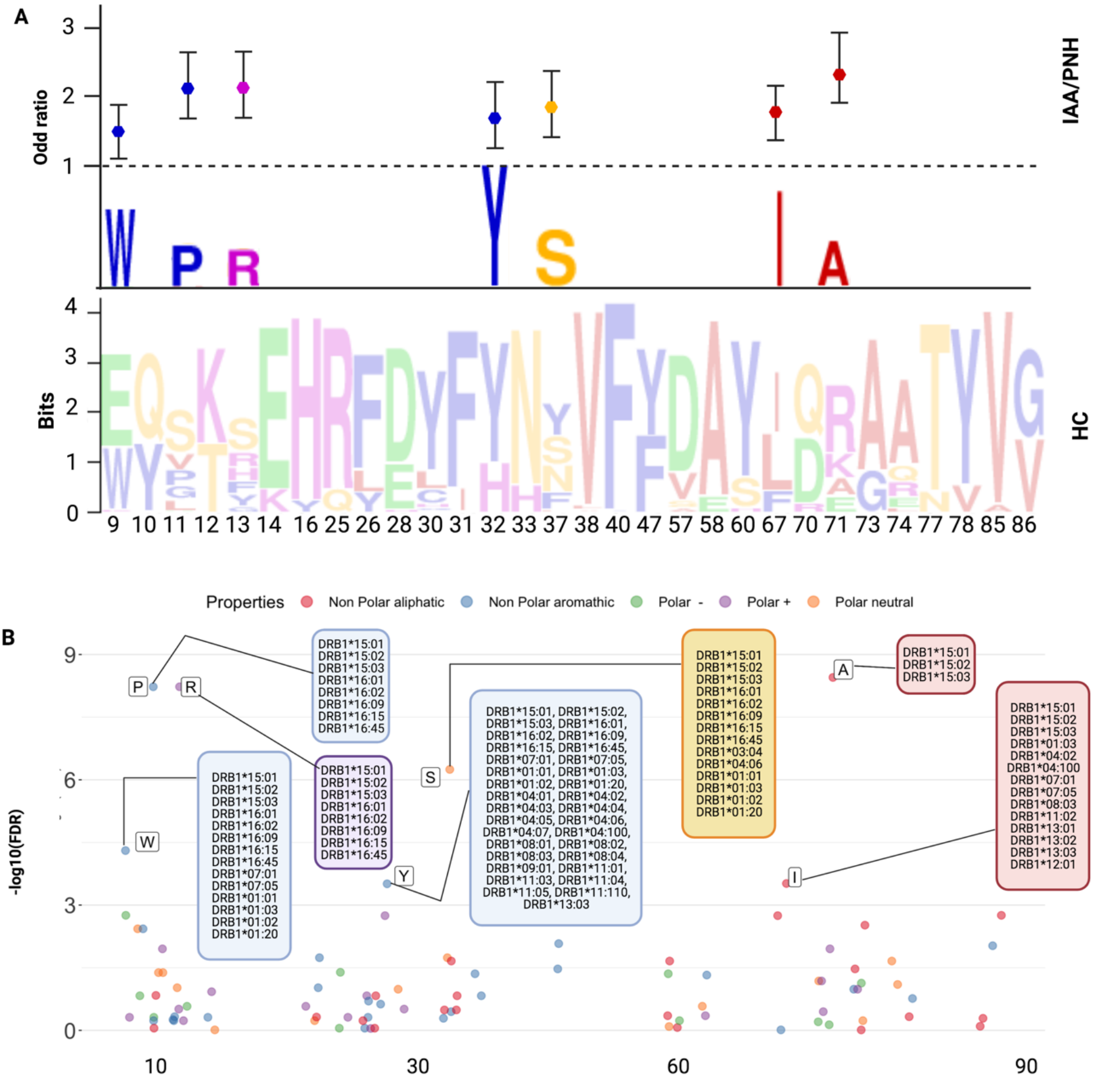

aa Position peptide binding site DRB1 locus

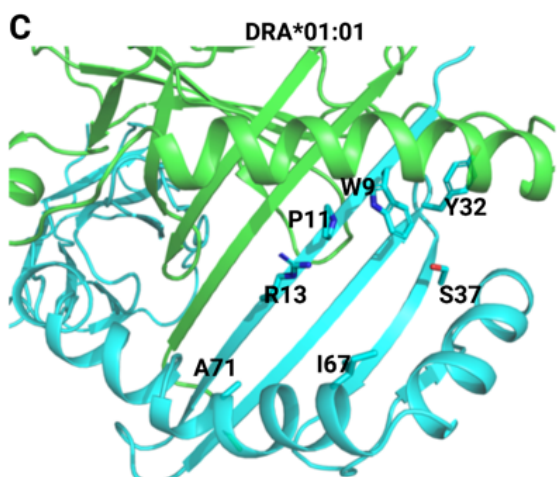

DRB1*15:01

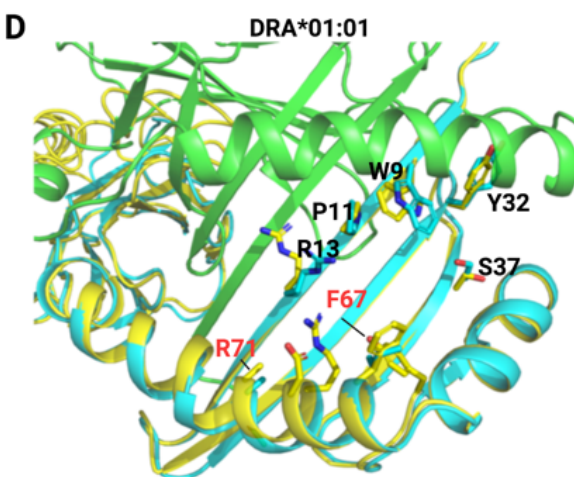

DRB1*16:01

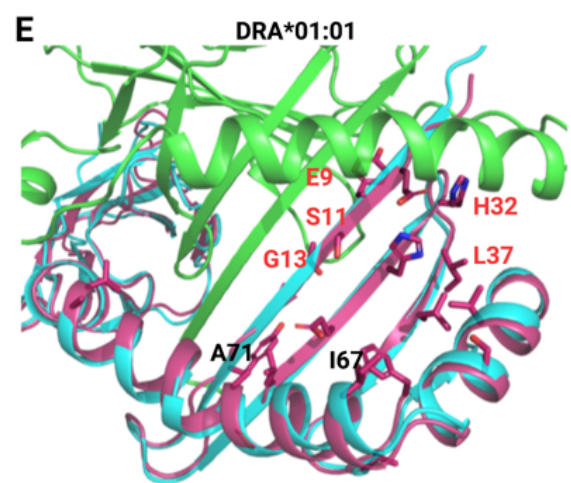

DRB1*12:01 
medRxiv preprint doi: https://doi.org/10.1101/2021.05.28.21258028; this version posted June 3, 2021. The copyright holder for this preprint (which was not certified by peer review) is the author/funder, who has granted medRxiv a license to display the preprint in perpetuity. It is made available under a CC-BY-NC-ND 4.0 International license.

Immunogenetic basis of BMF

Pagliuca et al. 2021

\section{Figure 5: Recursive analysis of the amino acid sequence within the peptide binding site of DRB1 locus}

Abbreviations: IAA: Idiopathic aplastic anemia; PNH: paroxysmal nocturnal hemoglobinuria; HC: healthy controls; aa: amino acid

A) Lower panel: WebLogo visualization representing the contribution of single aminoacids within the variable portion of the peptide binding site of DRB1 locus. The $x$-axis indicates each variable position (as per IPD-IMGT-HLA reference). Letters represent each possible amino acid at each given position; Letters' height illustrates the frequency of each amino acid in healthy control population. Colors indicate the chemicophysical properties as per legend in B.

Upper panel: stylized visualization of amino acids differentially distributed between HC and IAA/PNH cohorts. Letters' height illustrates the frequency of each amino acid in disease population. Markers indicate the odd ratios resulting from the logistic regression analysis studying each aminoacidic contribution in determining the phenotype (see methods and Table S7).

B) Scatter plot showing the significance level of each variable amino acid in the peptide binding site of DRB1 locus found enriched in IAA/PNH population compared to HC. Each dot represents the negative logarithm base 10 for the adjusted $p$-value (q-value) referring to each amino acid. The position on $x$-axis indicate the position within the peptide binding site according to IPD-IMGT-HLA reference). Only the amino acids presenting a q-value $<10$-e4 are considered significant for this analysis and labelled in the figure. Alleles presenting the indicated amino acid at the given position are indicated in the boxes. Colors represent the chemico-physical properties as per legend.

C) Crystallographic structure showing the position of the 7 amino acids significantly enriched in the peptide binding groove of DR molecules of IAA/PNH patients. This 3D structure has been visualized with the PyMOL program based on the structure of DRB1*15:01-DRA*01:01-myelin binding protein (PDB:1BX2) and HLA sequences retrieved from IPD-IMGT/HLA database v. 3.40. Only the 7 amino acids identified in the previous analysis have been highlighted.

D) Binding site of DRB1*16:01-DRA*01:01 based on the homology model of DRB1*16:01. The structure of DRB1*16:01 has been superimposed to DRB1*15:01. Residues differing from the risk pattern seen in DRB1*15:01 are colored in red.

E) Binding site of DRB1*12:01-DRA*01:01 based on the homology model of DRB1*12:01. The structure of DRB1*12:01 has been superimposed to the structure of DRB1*15:01. Residues differing from the risk pattern seen in DRB1*15:01 are colored in red. 
medRxiv preprint doi: https://doi.org/10.1101/2021.05.28.21258028; this version posted June 3, 2021. The copyright holder for this preprint (which was not certified by peer review) is the author/funder, who has granted medRxiv a license to display the preprint in perpetuity. It is made available under a CC-BY-NC-ND 4.0 International license.

Immunogenetic basis of BMF

Pagliuca et al. 2021

Figure 6

A

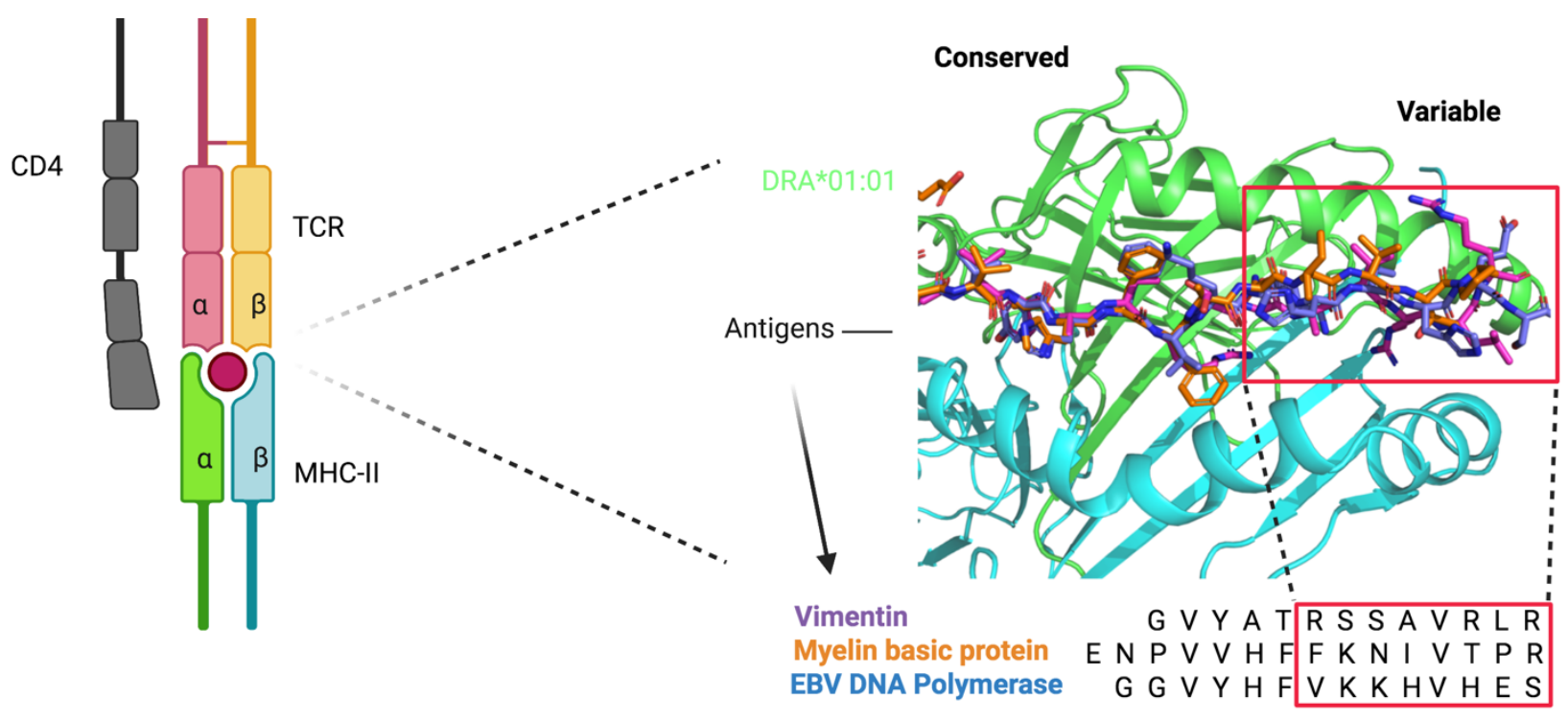

B

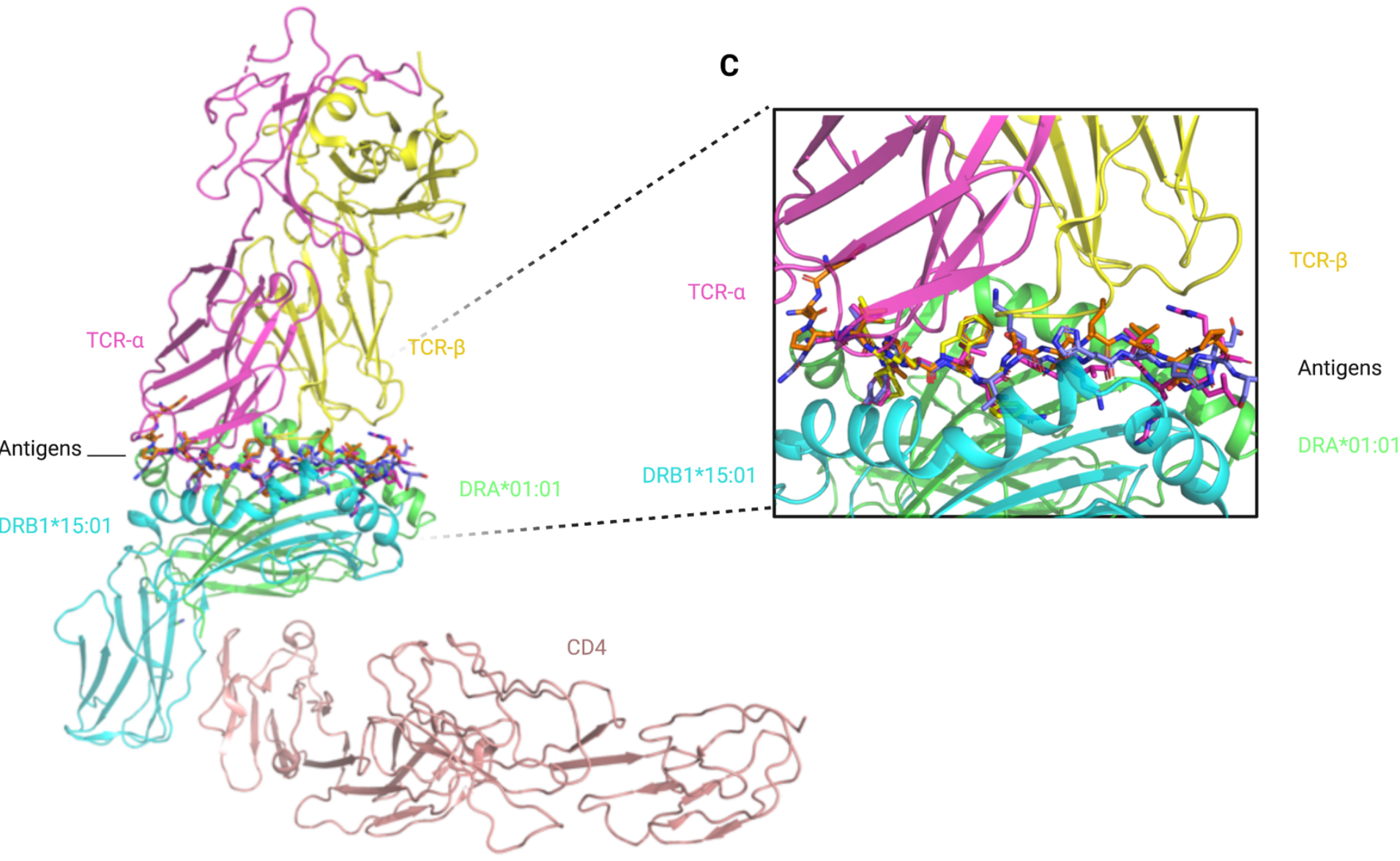


medRxiv preprint doi: https://doi.org/10.1101/2021.05.28.21258028; this version posted June 3,2021 . The copyright holder for this preprint (which was not certified by peer review) is the author/funder, who has granted medRxiv a license to display the preprint in perpetuity. It is made available under a CC-BY-NC-ND 4.0 International license .

Immunogenetic basis of BMF

Pagliuca et al. 2021

Figure 6: Structural insight into DRB1-antigen-TCR interactions

Abbreviations: TCR: T-cell receptor; MHC: major histocompatibility complex, MBP: myelin binding protein; EBV: Epstein barr virus

A) Peptides of vimentin (UniProt: P08670, VIME_HUMAN, 59-71), EBV DNA polymerase (UniProt: P03198, DPOL_EBVB9, 628-641), MBP (UniProt: P02686, MBP_HUMAN, 217-231) at the HLA binding site based on the alignment of crystal structures of DRB1*15:01-DRA*01:01/MBP (217-231) (PDB: 1BX2), DRB1*14:02-DRA*01:01/ vimentin (amino acid positions: 59-71, PDB:1H15) and DRB5*01:01DRA*01:01/EBV DNA polymerase (628-641) (PDB:6ATF). The red squares indicate the peptide portions presenting with more conformational variability (in interaction with the right site of the HLA binding groove). This 3D structure has been prepared with PyMOL using the crystal structure of DRB1*15:01DRA*01:01/MBP (PDB: 1BX2).

B) Modeled ternary structure of HLA-Antigen-TCR-CD4.

C) Detail of the interaction interface in HLA-antigen-TCR. The three antigenic structures are aligned as shown above. The risk amino acid pattern within the right side of the binding groove interacts with a more variable antigenic portion that contacts directly with the TCR beta chain (software PyMOL). 
medRxiv preprint doi: https://doi.org/10.1101/2021.05.28.21258028; this version posted June 3, 2021. The copyright holder for this preprint (which was not certified by peer review) is the author/funder, who has granted medRxiv a license to display the preprint in perpetuity. It is made available under a CC-BY-NC-ND 4.0 International license.

Immunogenetic basis of BMF

Pagliuca et al. 2021

Figure 7

A

DRB1 locus

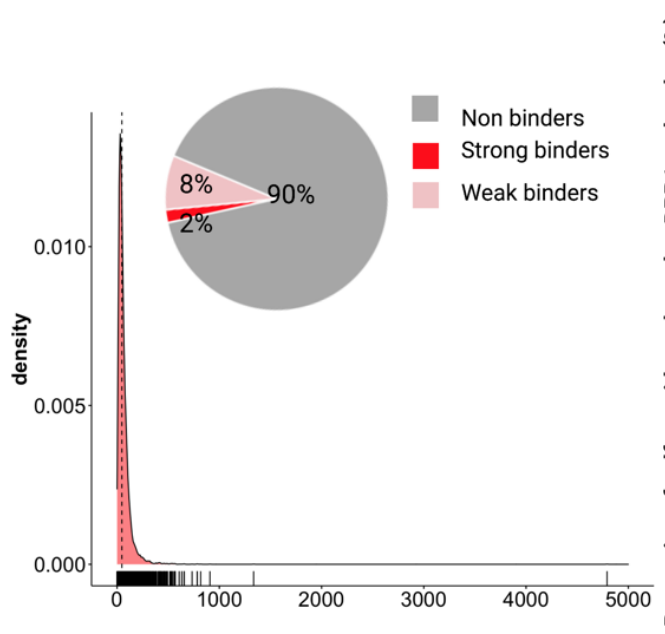

Mean \# binders per transcript
B

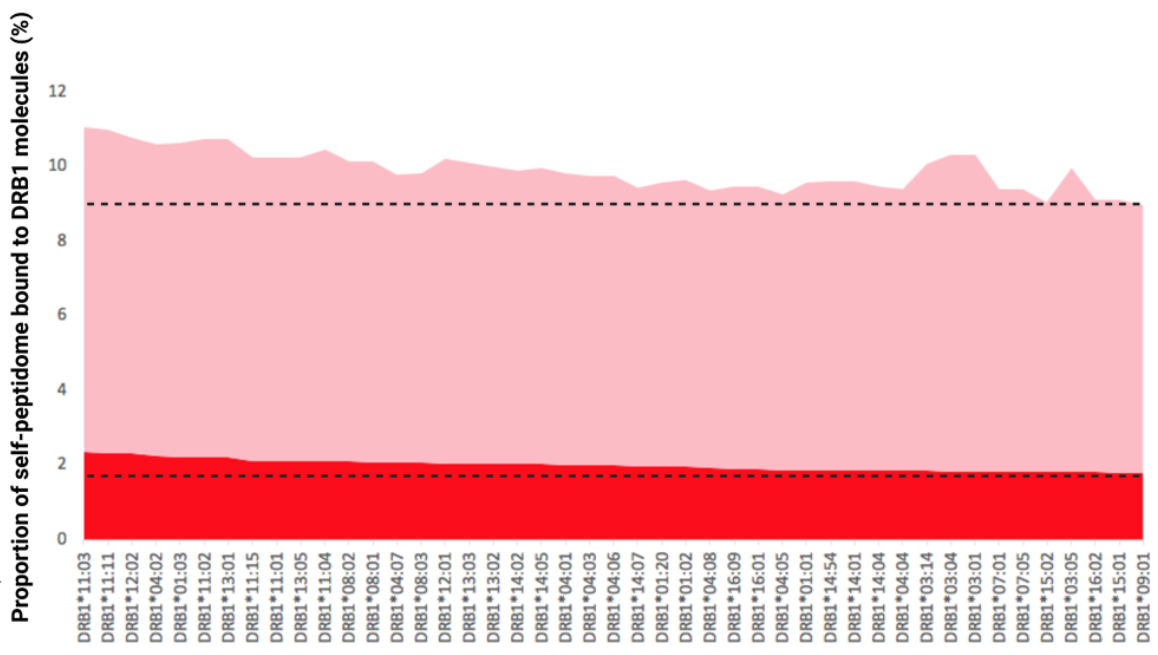

C

Top 100 coding genes associated with self-peptide formation

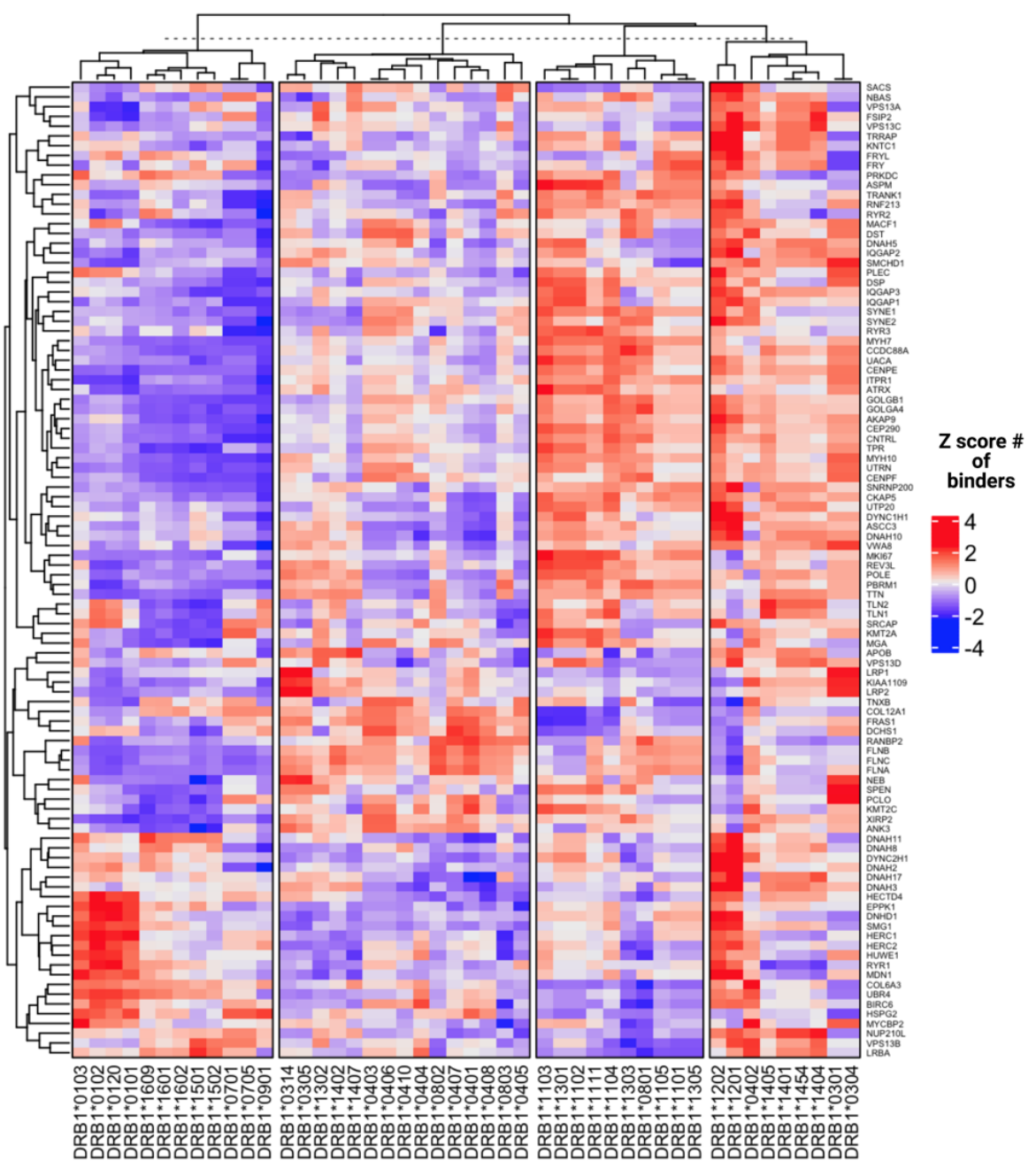

D
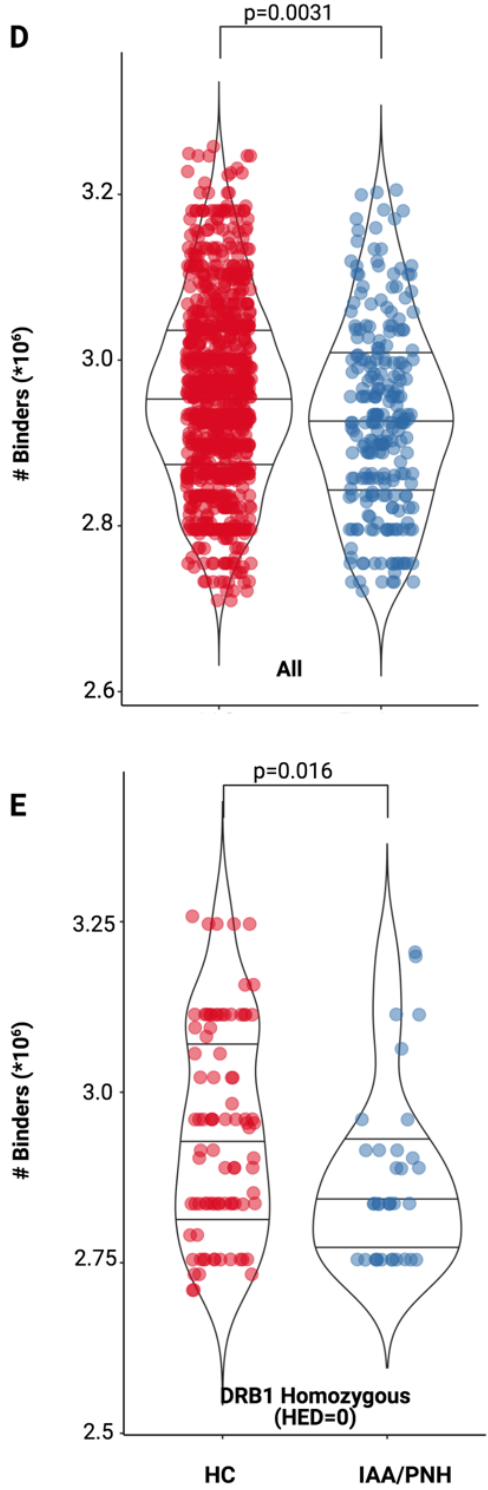
medRxiv preprint doi: https://doi.org/10.1101/2021.05.28.21258028; this version posted June 3,2021 . The copyright holder for this preprint (which was not certified by peer review) is the author/funder, who has granted medRxiv a license to display the preprint in perpetuity. It is made available under a CC-BY-NC-ND 4.0 International license .

Immunogenetic basis of BMF

Pagliuca et al. 2021

Figure 7: Hematopoietic stem cell specific immune-peptidome binding capacities of the DRB1 molecules.

Abbreviations: IAA: Idiopathic aplastic anemia; PNH: paroxysmal nocturnal hemoglobinuria; HC: healthy controls; HSC: hematopoietic stem cell; HED: HLA evolutionary divergence.

A) Density plot showing the mean number of binders per each transcript (average of number of strong and weak binders for all DRB1 molecules in study generated from the HSC-specific proteomic reference). The pie chart indicate the proportion of binders and non-binders for the whole reference. Overall $10 \%$ of this proteomic repertoire is able to generate potential self-peptides.

B) Filled 2D area plot representing the binding capacities of each DRB1 molecule in study for the self peptidomic HSC reference. $Y$-axis indicate the percentage (\%) of self-peptides predicted to bind DRB1 molecules. Red portion indicate strong binders, pink portion of the graph depicts instead weak binders (see methods).

C) Heatmap showing the top-100 coding genes associated with the self-peptidome formation. Each cell represents the Z-score of the number of binders predicted of each transcript for a given DRB1 molecule.

D) Distribution of the number of binders in $\mathrm{HC}$ and IAA/PNH cohorts. Wilcoxon signed rank test.

E) Distribution of the number of binders in $\mathrm{HC}$ and IAA/PNH homozygous subjects $(H E D=0)$. Wilcoxon signed rank test. 
medRxiv preprint doi: https://doi.org/10.1101/2021.05.28.21258028; this version posted June 3, 2021. The copyright holder for this preprint (which was not certified by peer review) is the author/funder, who has granted medRxiv a license to display the preprint in perpetuity. It is made available under a CC-BY-NC-ND 4.0 International license .

Immunogenetic basis of BMF

Pagliuca et al. 2021

Table 1: Patient characteristics

\begin{tabular}{|c|c|c|}
\hline All & $\mathbf{N}$ & 263 \\
\hline Age (years) & median (IQR) & $44(27-62)$ \\
\hline \multirow[t]{4}{*}{ Race } & Caucasian & $228(86 \%)$ \\
\hline & African American & $23(8 \%)$ \\
\hline & Asian & $9(4 \%)$ \\
\hline & Multiracial & $3(2 \%)$ \\
\hline \multirow[t]{2}{*}{ Gender } & Female & $132(50.2 \%)$ \\
\hline & Male & $131(49.8 \%)$ \\
\hline \multirow[t]{3}{*}{ Disease phenotype at diagnosis } & IAA +/- non-hemolytic PNH clone & $222(85 \%)$ \\
\hline & IAA + hemolytic PNH clone & $14(5 \%)$ \\
\hline & Primary hemolytic PNH & $27(10 \%)$ \\
\hline \multirow[t]{2}{*}{ Severity IAA } & Severe & $173(73 \%)$ \\
\hline & Moderate & $63(27 \%)$ \\
\hline \multirow[t]{2}{*}{ Response to IST* (first line) } & CR/PR & $135(69 \%)$ \\
\hline & NR & $59(31 \%)$ \\
\hline Secondary PNH from IAA & $\mathbf{N}(\%)$ & $30(13 \%)$ \\
\hline Progression to AML/MDS & $\mathbf{N}(\%)$ & $32(12 \%)$ \\
\hline Time to secondary PNH & median (IQR) & $49.2(26.7-122.6)$ \\
\hline Time to progression AML/MDS & median (IQR) & $39.7(20.3-71)$ \\
\hline Follow-up (months) & median (IQR) & $70.8(30-140)$ \\
\hline
\end{tabular}

Abbreviations: IQR: Interquartile range, IAA: Idiopathic aplastic anemia, PNH: Paroxysmal Nocturnal Hemoglobinuria; AML: Acute Myeloid Leukemia; MDS: Myelodysplastic syndrome; IST: Immunosuppressive treatment * Overall 194 patients received IST 